DIW BERLIN

Discussion Papers

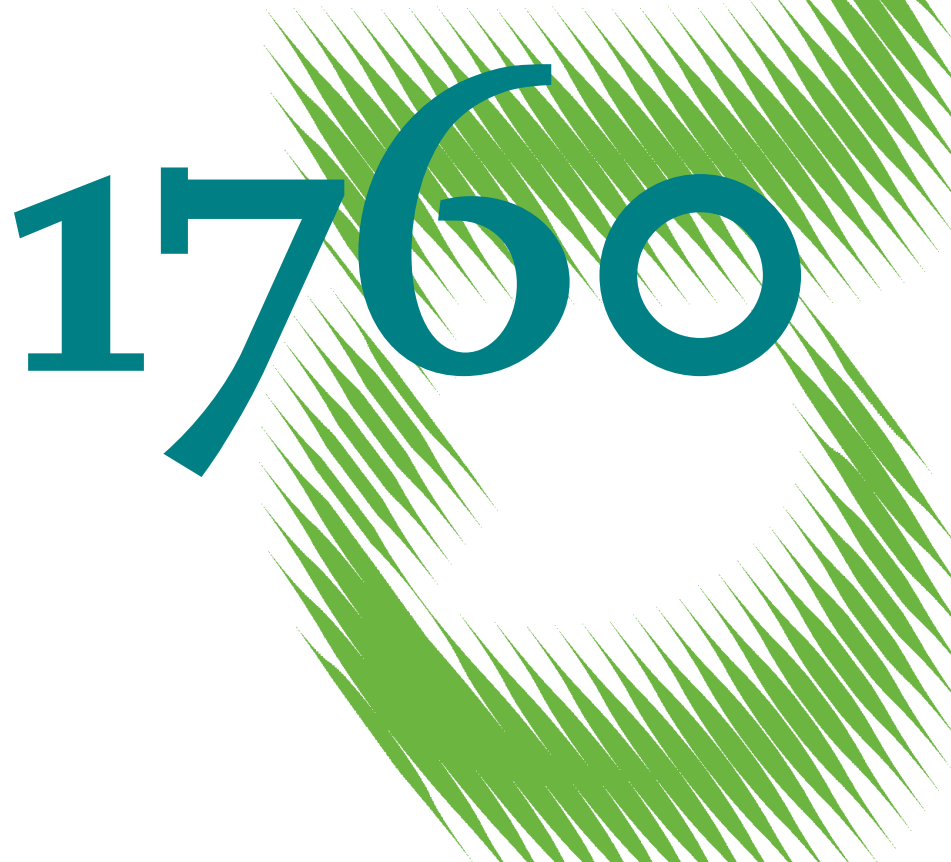

Intra-Household Risk Sharing and Job Search over the Business Cycle 
Opinions expressed in this paper are those of the author(s) and do not necessarily reflect views of the institute.

IMPRESSUM

(C) DIW Berlin, 2018

DIW Berlin

German Institute for Economic Research

Mohrenstr. 58

10117 Berlin

Tel. +49 (30) $89789-0$

Fax +49 (30) $89789-200$

http://www.diw.de

ISSN electronic edition 1619-4535

Papers can be downloaded free of charge from the DIW Berlin website:

http://www.diw.de/discussionpapers

Discussion Papers of DIW Berlin are indexed in RePEc and SSRN:

http://ideas.repec.org/s/diw/diwwpp.html

http://www.ssrn.com/link/DIW-Berlin-German-Inst-Econ-Res.html 


\title{
Intra-Household Risk Sharing and Job Search over the Business Cycle
}

\author{
Haomin Wang ${ }^{\mathrm{a}, 1, *}$ \\ ${ }^{a}$ DIW Berlin, Mohrenstraße 58, 10117 Berlin
}

\begin{abstract}
This paper studies the extent to which working couples can insure one another against cyclical fluctuations in the labor market and examines the implications of joint household decision-making for cyclical fluctuations in the unemployment rate. For this purpose, I provide a dynamic life-cycle model of households that make joint savings and job search decisions in the presence of aggregate shocks. I show that two key mechanisms are at play. The first is the added-worker effect, which leads to counter-cyclical search intensity because workers increase search intensity when their spouse becomes unemployed. The second is the comparative advantage effect, according to which couples' job search efforts are coordinated based on the relative returns to search of each spouse. I estimate the model using data from the US Current Population Survey, and find that joint household decision-making contributes to the counter-cyclicality of women's unemployment rate, but not for men. Moreover, joint household decision-making lowers the welfare costs of cyclicality.

Keywords: Joint Decision-Making, Cyclical Fluctuations, Unemployment Rate, Search Intensity, Intra-Household Risk Sharing

JEL: J64, E32, D10
\end{abstract}

\section{Introduction}

Transitions between non-participation and unemployment display strong cyclical patterns, suggesting that non-employed workers are more likely to search for a job in economic downturns. ${ }^{2}$ These transitions also

\footnotetext{
* Corresponding author

Email address: hwang@diw.de (Haomin Wang)

${ }^{1}$ I am very grateful to John Kennan, Rasmus Lentz, and Nicolas Roys for their advice and guidance. I thank Chris Taber, Suphanit Piyapromdee, Luke Haywood, François Fontaine, as well as seminar participants at the Empirical Micro Workshop and the Labor Seminar at the University of Wisconsin-Madison for their excellent comments. The computations in this paper are carried out at the Flash High Performance Computing Cluster maintained by the Social Science Computing Cooperative at UW-Madison. All errors are mine.

${ }^{2}$ In the US Current Population Survey (CPS), the transition rate from non-participation to unemployment is counter-cyclical, while the transition rate from unemployment to non-participation is pro-cyclical (see Appendix Appendix A.1). These transitions reflect changes in job search behaviors because non-employed individuals who actively search for employment are classified as unemployed workers.
} 
vary significantly across spousal labor force status, which suggests that the job search decision is made at the household level rather than the individual level. ${ }^{3}$

Existing literature such as Guler et al. (2012) shows that, when couples are risk-averse and imperfectly insured, the interactions between spouses can lead to labor market behaviors that are significantly different from those of singles. Over the business cycle, job search of married individuals can be affected by their spouse's employment prospects and outcomes. Since job search decisions affects the job finding rate the determines whether a non-employed individual is classified as an unemployed worker, making search decisions jointly with a spouse has empirical implications for cyclical fluctuations of the unemployment rate. In the meantime, as joint decision-making enables spouses to share risks with each other, couples may experience reduced welfare costs of cyclical fluctuations compared to individuals who make decisions independently.

Cyclical implications of joint household decision-making are not well explored in the literature. The goal of this paper is to study the extent to which working couples can insure one another against cyclical fluctuations in the labor market and to examine the implications of joint decisions for cyclical fluctuations in the unemployment rate. With over half of the adult population in the U.S. being married, a better understanding of the role of joint decision-making offers valuable insights for policymakers in assessing labor market slacks and designing appropriate policy measures.

To this end, I construct and estimate a life-cycle model of married-couple households in the presence of cyclical fluctuations in the labor market. Specifically, each household is formed by a married couple that acts as a unitary decision maker. ${ }^{4}$ Couples are risk-averse and imperfectly insured due to incomplete financial markets and borrowing constraints. When seeking employment, couples choose search intensity: Higher search intensity increases the job finding rate but also incurs greater costs. The job finding rate per unit of search intensity fluctuates over the business cycle.

I distinguish unemployment from non-participation using a threshold rule on search intensity: those who search intensively are classified as unemployed workers and the others as non-participants. This allows me to simulate labor force stock and flow statistics from the model, which are matched to their data counterparts in order to estimate the model parameters using the indirect inference technique. Estimation of the model is based on a sample of married-couple households drawn from the US Current Population Survey (CPS) between 1994 and 2014 with the sample stratified by the education levels of the couples.

In the model, there are two main mechanisms through which joint decision-making affects cyclical fluctuations

\footnotetext{
${ }^{3}$ Based on the CPS, spousal unemployment is associated with a higher transition rate from non-participation to unemployment and a lower transition rate in the opposite direction (see Appendix Appendix A.2). This is in line with Lundberg (1985) and Juhn and Potter (2007), who find that women are more likely to join the labor force if their husband is unemployed rather than employed.

${ }^{4}$ The assumption not only ensures computational feasibility but also forms a stark contrast to the single-agent model that is the benchmark in the search literature.
} 
of search intensity. The first is the added-worker effect: Individuals search for jobs more intensively when their spouse is not employed; therefore, counter-cyclicality spousal non-employment leads to counter-cyclical search intensity. The second mechanism is the comparative advantage effect: The spouse facing less cyclical volatility in the labor market would be incentivized to search more counter-cyclically, and vice-versa.

Gender-asymmetry is allowed for in several dimensions in the model. Both the level and the cyclicality of the job finding rate per unit of search intensity may be different between men and women. In addition, the marginal cost of job search may vary differentially with search intensity for the two genders. The genderspecific parametrization captures differences in employment opportunities across industries and occupations, the usage of job search methods, and, possibly, taste for job search between men and women. Estimation results reveal substantial gender-asymmetry among households across all education levels. Compared to men, women face a less convex search cost function and thus their search intensity is more responsive to changes in the aggregate state and the spousal employment status. In addition, the job finding rate per unit of search intensity of married women is relatively less cyclical.

To assess the role of joint household decision-making over the business cycle, I compare the baseline model of married couples to a counterfactual one in which individuals make independent decisions. The results show that, for women, making joint decisions with their spouse significantly amplifies the counter-cyclicality of the unemployment rate. The effect is stronger among less-educated women. In contrast, the effect of joint decision-making on the cyclicality of men's unemployment rate is ambiguous.

In addition to the cyclicality of the unemployment rate, the simulation results also indicate that joint decisionmaking by couples reduces the welfare cost of cyclical fluctuations, computed as a percentage increase in the lifetime welfare if there were no cyclical fluctuations. Married-couple households face an average welfare cost of $0.6 \%$ due to cyclical fluctuations. If spouses did not make joint decisions, the welfare cost would rise by around 0.3 percentage points, suggesting that joint decision-making is an effective way of insuring married couples against cyclical fluctuations. This is consistent with Shore (2010)'s finding that marriage makes the riskiness of incomes less counter-cyclical. Furthermore, echoing Ortigueira and Siassi (2013)'s finding that joint decision-making is most valued by wealth-poor households, my simulation results show that couples that are unlucky in the labor market and unable to accumulate wealth find joint decision-making most valuable in reducing the welfare cost of cyclical fluctuations. This is true for all households in which at least one spouse do not have a college degree.

The paper is closely related to the growing literature that examines the economic implications of joint decision-making by couples facing unemployment risk and wage uncertainties. Compared to singles, couples have different motives in making job search decisions because they can share risks with each other. Guler et al. (2012), Flabbi and Mabli (2018), and Blundell et al. (2016) show that intra-household risk sharing has empirical ramifications for lifetime incomes, labor force transitions, lifetime inequality, and consumption 
inequality. As couples can self-insure through risk sharing, Haan and Prowse (2017) show that the optimal generosity of social assistance for couples is significantly lower compared to singles. Besides risk sharing, Dey and Flinn (2008) study employer-provided health insurance as a public good within married-couple households. Guler et al. (2012) consider a multiple-location model of couples facing costs of living apart.

Relative to this literature, the contribution of this paper is to examine the role of joint decision-making over the business cycle. A closely related work is Mankart and Oikonomou (2017), who show that incorporating joint decision-making allows for a better match of cyclical volatilities in aggregate labor market measures, which is a challenge for single-agent models with endogenous participation decision (Tripier, 2004; Veracierto, 2008). Although Mankart and Oikonomou (2017) also focus on the business cycle, there are a number of differences between our papers, one of which is the treatment of gender-asymmetry. In their model, the two genders are ex-ante identical. In my paper, because of the gender-specific parameterization, I find joint decision-making to be a more important driving force behind the counter-cyclicality of women's unemployment rate.

Differences across genders in the cyclicality of labor supply and unemployment have been shown to be important. Hoynes et al. (2012) and Albanesi and Sahin (2018) find that women's labor supply and unemployment are less cyclical compared to men, with industry and occupation being important factors explaining this observation. Doepke and Tertilt (2016) show that, although female labor supply may have higher wage elasticity at the individual level, there is less cyclical volatility in women's aggregate labor supply even after controlling for industry effects. They argue that women's greater role in household self-insurance may have a dampening effect on the cyclicality of their labor supply. The findings in this paper support their view.

This paper's specification of the job search decision is also different from Mankart and Oikonomou (2017). They assume a binary job search decision, while I consider a multi-level search intensity decision that is motivated by the empirical evidence that there is rich heterogeneity in labor force attachment among the non-employed (Jones and Riddell, 2006; Faberman et al., 2017). In my estimated model, there is a positive correlation between the level and the counter-cyclicality of search intensity. The correlation is particularly pronounced among women, which has empirical ramifications. In the Appendix, I study a version of the model in which there exist only binary search decisions and show that such a model performs poorly in matching cyclical fluctuations in women's labor force participation rate.

The rest of the paper is organized as follows. In Section 2, I introduce the life-cycle model of married couples and its implications for the cyclicality of search intensity. I discuss the estimation method in Section 3 and present estimation results in Section 4. In Section 5, I demonstrate the empirical implications of joint decision-making by comparing the married-couple model with a counterfactual individualist model. Finally, I conclude the paper in Section 6. 


\section{The Model}

Motivated by the empirical observations documented in Appendix Appendix A that transitions between nonparticipation and unemployment are cyclical and dependent on spousal labor force status, I propose a model in which married couples face cyclical fluctuations in the labor market and make consumption and job search decisions as unitary decision-makers.

\subsection{Model Environment}

Each household consists of two individuals, a husband $(i=h)$ and a wife $(i=w)$. Time is discrete. The life horizon spans a working stage and a retirement stage that consist of $\tau_{\text {work }}$ and $\tau_{\text {ret }}$ periods respectively. Each period corresponds to a calendar month. During each period of the working stage, an individual is either employed $\left(l_{i}=1\right)$ or non-employed $\left(l_{i}=0\right)$. An employed individual may become separated from employment in the next period with probability $\delta_{i, z}$ that depends on the aggregate state $z$.

A non-employed individual engages in job search with intensity $s_{i}$. Although $s_{i}$ is not directly observable, the CPS collects information on job search methods that non-employed individuals use and classifies those who use active job search methods as unemployed workers. ${ }^{5}$ Thus, it is plausible to associate unemployment with higher search intensities.

Higher search intensity also increases the job finding rate, which is given by

$$
\lambda\left(s_{i}, \lambda_{i, z}\right)=\min \left\{1, s_{i} \lambda_{i, z}\right\} \text { for } i=h, w .
$$

$\lambda_{i, z}$ 's are baseline job-finding rates, representing the effectiveness of job search per unit of search intensity. For convenience, I define $\lambda_{i, 0} \equiv \lambda_{i, B}$ and $\lambda_{i, 1} \equiv \lambda_{i, G}-\lambda_{i, B}$, so that $\lambda_{i, 0}$ captures the "average" level of search effectiveness and $\lambda_{i, 1}$ captures the cyclicality. I allow the baseline job finding rate to differ across genders to account for potential differences between men and women in employment opportunities across industries and occupations.

Higher search intensity also incurs a higher disutility, which reflects distaste for exerting search effort relative to the value of the forgone time that could be spent at home. The search disutility function is

$$
k_{i}\left(s_{i}\right)=\kappa_{i, 0} s_{i}^{\kappa_{i, 1}} \text { for } i=h, w,
$$

where $\kappa_{i, 0}>0$ and $\kappa_{i, 1}>1$. Given that the job finding rate is linear in search intensity, the assumption that disutility of job search increases more than proportionally is in line with diminishing marginal returns to

\footnotetext{
${ }^{5}$ For example, answering job advertisements is considered as an active search method, while reading job advertisements is considered as a passive search method. See Table C.13 for the list of search methods in the CPS.
} 
search. The gender-specific $k_{i}(\cdot)$ implies that men and women may experience different marginal disutilities when searching with the same intensity as a result of different job search methods or differences in their taste for spending time at home. In Appendix Appendix C.1, I document differences in the choice of job search methods between men and women based on the CPS. I show that, among active job seekers, married women are more likely to send resumes but less likely to contact employers relative to married men.

Overall, the gender-specific parametrization is important for the model's empirical performance, which I discuss in Section 4.3.

Non-employed individuals are subject to the $\eta$-shock with probability $\pi_{\eta, i} \equiv \operatorname{Pr}\left(\eta_{i}=1\right)$. When $\eta_{i}=1$, the individual is unable to conduct job search $\left(s_{i}=0\right)$. The shock is transient and individuals under the $\eta$-shock recover from it in the following period. The shock captures unexpected incidences such as sickness or family emergencies that temporarily prevent one from engaging in job search activities.

An employed individual receives wage $w_{i}$. I assume a degenerate wage offer distribution that is constant throughout one's lifetime. ${ }^{6}$ Since all jobs that an individual encounters are identical, I use the terms "job" and "employment" interchangeably in this paper. The assumption of a degenerate wage distribution greatly simplifies the model because an employed individual has no incentive to quit or search on-the-job. Men and women may receive different wages. In simulating data from the model, I also allow for additional wage heterogeneity across different households.

A non-employed individual receives non-employment income $w_{i}^{n}=\mu^{n} w_{i}$ with fixed non-employment income ratio $\mu^{n} \cdot{ }^{7}$ In the retirement stage, an individual can be neither employed nor searching for work; he or she receives retirement income $w_{i}^{r}$ that depends on wage $w_{i}$.

Each individual derives utility $u\left(c_{i}\right)$ from his or her consumption. The utility function exhibits constantrelative-risk-aversion (CRRA):

$$
u\left(c_{i}\right)= \begin{cases}\frac{1}{4} \frac{c_{i}^{(1-\gamma)}}{(1-\gamma)} & \gamma>0, \gamma \neq 1 \\ \frac{1}{4} \ln \left(c_{i}\right) & \gamma=1\end{cases}
$$

The disutility from search and utility from consumption are additively separable. Lentz and Tranaes (2005) show that with additively separable utility, a risk-averse worker's search intensity decreases in wealth. This is a pattern consistent with the empirical findings that wealth lowers the job-finding rate of unemployed workers (Alexopoulos and Gladden, 2004; Card et al., 2007; Stancanelli, 1999).

\footnotetext{
${ }^{6}$ In Appendix Appendix G, I consider a version of the model with cyclical fluctuations in wages and in the gender wage gap as a robustness check. I show that allowing for plausible cyclical variations in wages does not alter the conclusions of the paper.

${ }^{7}$ In this paper, I do not model the taxes and transfers of social welfare programs such as the Unemployment Insurance (UI), so $w_{i}^{n}$ should not be interpreted as UI benefits.
} 
Couples can save but are not allowed to borrow. They collect returns on savings at rate $r$ per period. Savings is the only type of asset that couples can accumulate; therefore, throughout this paper, I use the terms "savings", "asset", and "wealth" interchangeably.

Each couple acts as a unitary decision-maker. The unitary household model is commonly used to study joint household decisions in the search literature. It is a useful framework because of its empirical tractability and its stark contrast to the benchmark single-agent model. Contrary to single-agent models that assume no risk sharing between individuals, unitary household models assume that spouses are fully committed to marriage, enabling them to share risks with one another to the fullest extent. ${ }^{8}$

The life cycle of couples terminates at the end of the retirement stage. Although couples do not choose the retirement age or face any uncertainty in retirement, having a retirement stage is important because retirement is another motive for wealth accumulation besides consumption smoothing.

The aggregate state $z$ follows a two-state Markov process. A Good state $(z=G)$ differs from a $\operatorname{Bad}(z=B)$ in that the baseline job finding rates are higher. $\pi_{z^{\prime} \mid z}$ denotes the monthly aggregate state transition rate from state $z$ to state $z^{\prime}$.

To keep the model tractable, I do not consider equilibrium effects of job search decisions. A matching function à la Mortensen and Pissarides (1994) would imply that higher aggregate search intensity lowers the baseline job finding rate for all job seekers. However, in my model, I expect the equilibrium effect to be small compared to the direct effect deriving from differential search intensity. ${ }^{9}$ This is because simulated households are highly heterogeneous in the household asset level, which is an important determinant for the cyclicality of search intensity.

\subsection{Value Functions}

The working stage lasts for $\tau_{\text {work }}$ periods. At the beginning of each period, couples observe their wealth level $a$, employment statuses $l_{h}$ and $l_{w}$, the aggregate state $z$, and the realization of $\eta$-shocks $\eta_{h}$ and $\eta_{w}$. They choose consumption levels $c_{h}$ and $c_{w}$, and search intensities $s_{h}$ and $s_{w}$ in order to maximize the present value of discounted net utility. The present value in period $\tau \leq \tau_{\text {work }}$ is

$$
V_{\tau}\left(a, l_{h}, l_{w}, z, \eta_{h}, \eta_{w}\right)=\max _{\left\{c_{i}, s_{i}\right\}_{i=h, w}}\left\{\sum_{i=h, w}\left[u\left(c_{i}\right)-k_{i}\left(s_{i}\right)\right]+\beta \mathbf{E} V_{\tau+1}\left(a^{\prime}, l_{h}^{\prime}, l_{w}^{\prime}, z^{\prime}, \eta_{h}^{\prime}, \eta_{w}^{\prime}\right)\right\},
$$

\footnotetext{
${ }^{8}$ An alternative to the unitary model is a collective model in which household members are not fully committed. See Chiappori and Mazzocco (2017) for a survey of household models with different degrees of commitment. The strategic element in a collective model limits the extent of risk sharing between spouses. Thus, in this paper, conclusions drawn from the comparison between the unitary household model and the individualist model can be seen as an upper bound for the effects of joint household decision-making.

${ }^{9}$ Based on simulated data from the model with parameters estimated from the CPS data, the aggregate search intensity is acyclical.
} 
subject to

$$
\begin{aligned}
s_{i} & \in S\left(l_{i}, \eta_{i}\right) \text { for } i=h, w \\
0 \leq a^{\prime} & \leq(1+r) a+\sum_{i=h, w}\left[w_{i} l_{i}+w_{i}^{n}\left(1-l_{i}\right)-c_{i}\right] .
\end{aligned}
$$

The state variables are $a \in[0, \infty), l_{i}$ and $\eta_{i} \in\{0,1\}$ for $i=h, w$, and $z \in\{G, B\}$. $\beta$ is the subjective discount factor. The expectation in the value function is taken over $\left\{l_{h}^{\prime}, l_{w}^{\prime}, z^{\prime}, \eta_{h}^{\prime}, \eta_{w}^{\prime}\right\}$, with the prime notation denoting objects in period $\tau+1$. The transition rates are

$$
\begin{aligned}
\operatorname{Pr}\left(l_{i}^{\prime}=1 \mid l_{i}=0\right) & =\lambda\left(s_{i}, \lambda_{i, z}\right) \text { for } i=h, w ; \\
\operatorname{Pr}\left(l_{i}^{\prime}=0 \mid l_{i}=1\right) & =\delta_{i, z} \text { for } i=h, w ; \\
\operatorname{Pr}\left(\eta_{i}^{\prime}=1 \mid \eta_{i}=0\right) & =\pi_{\eta, i} \text { for } i=h, w ; \\
\operatorname{Pr}\left(\eta_{i}^{\prime}=0 \mid \eta_{i}=1\right) & =1 \text { for } i=h, w ; \\
\operatorname{Pr}\left(z^{\prime} \mid z\right) & =\pi_{z^{\prime} \mid z} \text { for } z^{\prime}=G, B .
\end{aligned}
$$

$S\left(l_{i}, \eta_{i}\right)$ is the set of feasible search intensities conditional on $l_{i}$ and $\eta_{i}$. If $l_{i}=1$ or $\eta_{i}=1$, the set is $\{0\}$. If $l_{i}=0$ and $\eta_{i}=0$, the set becomes nontrivial and is denoted by $\boldsymbol{S}$. A binary choice of whether or not to participate in the labor force is commonly assumed in the literature, but empirical findings support more flexible labor force attachments among the non-employed population. ${ }^{10}$ Using the CPS, Jones and Riddell (2006) find that marginally attached workers, defined as those who are available for work but not searching, have a statistically higher transition rate into employment compared to the rest of non-participants. Furthermore, according to the survey administered by Faberman et al. (2017), the researchers find that individuals who claim to be "unavailable for work" sometimes actively search for and receive job offers. For these reasons, I deviate from the binary choice of labor force participation and assume that $\boldsymbol{S}$ contains six levels of search intensity. This has empirical significance for the cyclicality of unemployment and labor force participation, which I discuss in Section 4.3.

It is useful to define unemployment and non-participation as two separate states of non-employment: A non-employed individual is classified as an unemployed worker if $s_{i}>\bar{s}$ and a non-participant if $s_{i}<\bar{s}$. I assume that the search intensity threshold $\bar{s}$ is the median of the set $\boldsymbol{S}$.

Individuals retire at the end of period $\tau_{\text {work }}$, after which the retirement stage starts and lasts for $\tau_{\text {ret }}$ periods. In retirement, couples choose consumption levels after observing the current wealth level $a$. The present

\footnotetext{
${ }^{10}$ For example, Mankart and Oikonomou (2017) assumes that the search intensity choice is binary and define unemployment and non-participation based on the choice.
} 
value at period $\tau$ such that $\tau_{w o r k}<\tau \leq \tau_{\text {work }}+\tau_{\text {ret }}$ is

$$
V_{\tau}\left(a, l_{h}, l_{w}, z, \eta_{h}, \eta_{w}\right)=V_{\tau}^{R}(a)=\max _{c_{h}, c_{w}}\left\{\sum_{i=h, w} u\left(c_{i}\right)+\beta V_{\tau+1}^{R}\left(a^{\prime}\right)\right\}
$$

subject to

$$
0 \leq a^{\prime} \leq(1+r) a+\sum_{i=h, w}\left(w_{i}^{r}-c_{i}\right)
$$

At the end of period $\tau_{w o r k}+\tau_{r e t}$, the household's life cycle terminates. I assume that the household does not derive utility from positive wealth upon death, that is, $V_{\tau_{w o r k}+\tau_{\text {ret }}+1}^{R}(a)=0$ for all $a \geq 0 .{ }^{11}$ The zero borrowing constraint also rules out death in debt.

Because the individual utility function is identical for the two genders, and because there is equal weight placed on the spouses' utility, the optimal decision is for each couple to share consumption equally, that is, $c_{h}=c_{w}$.

\subsection{Implications for the Cyclicality of Search Intensity}

The fact that job search decisions are made jointly has implications for the cyclicality of search intensity. To disentangle the various mechanisms in the model affecting cyclical fluctuations in search intensity, I study a simplified two-period model in Appendix Appendix B.

Joint decision-making by couples affects the cyclicality of search intensity mainly through the added-worker effect and the comparative advantage effect. The added-worker effect is due to the fact that non-employed individuals search more intensively when their spouse is also non-employed rather than employed. If spousal non-employment is counter-cyclical, the added-worker effect leads to counter-cyclical search intensity. The comparative advantage effect arises when a couple's baseline job finding rates vary differentially over the business cycle. If $\lambda_{i, 1}<\lambda_{j, 1}$, spouse $i$ has a greater comparative advantage in the labor market in the Bad state than in the Good state, and this would lead $i$ to search more counter-cyclically and $j$ less countercyclically.

The model also contains other mechanisms affecting the cyclicality of search intensity that are not unique to couples. One such mechanism is simply that an increase in the baseline job finding rate increases the returns to search and encourages higher search intensity. A second mechanism is the wealth effect, which entails that a wealth-poor household would rely even more heavily on job search than on accumulating savings in a weaker labor market as a way to smooth consumption.

\footnotetext{
${ }^{11}$ The lack of a bequest motive may lead to an under-prediction of savings. However, as I explain later, estimation of the model is based on simulated data of households between age 30 and 45 , and the life cycle of a simulated household terminates at age 75 . The bequest motive is likely to have a rather small influence on the search and saving decisions of households in their prime age.
} 
Search intensity determines both the job finding rate and the classification of non-employed individuals into unemployment or non-participation. Depending on whether search intensity fluctuates below, around, or above $\bar{s}$, the effects on the unemployment rate and the labor force participation rate are different. I give a detailed discussion in Section 4.3.

\section{Estimation}

\subsection{The Current Population Survey}

I use data from the Current Population Survey (CPS) from 1994 to 2014 to estimate the model. ${ }^{12}$ The CPS is a monthly survey conducted by the US Census Bureau to collect information from about 60,000 households that constitute a nationally representative sample. I identify married couples by linking household heads to their spouse. The CPS adopts a rotating panel design: A household is interviewed for two rotations, each lasting 4 consecutive months. The two rotations are eight months apart. The survey design allows me to construct monthly labor force transition rates. The CPS is a relatively large sample compared to other panel datasets such as the Panel Study of Income Dynamics; the feature is essential for producing accurate measures of labor force statistics such as the transition rates between non-participation and unemployment.

My sample contains civilian couples who are not disabled, retired or in school. In addition, I exclude couples whose marriage is formed or dissolved during a survey rotation. I consider two education levels: HS, which includes those who have completed high school but have no college degree, and COL, which includes those who have at least a college degree. I use $\mathrm{EDU}_{h}$-EDU $w$ to indicate the household education-composition, where $\mathrm{EDU}_{h}$ and $\mathrm{EDU}_{w}$ are education levels of husband and the wife, respectively. I estimate the model separately for each of the four groups of households: HS-HS, COL-COL, COL-HS, and HS-COL.

I restrict my sample to prime-age married couples in which at least one spouse is between 30 and 45 years of age. This allows me to focus on labor force decisions instead of life-cycle decisions like retirement. The final sample contains 2,222,090 household-months from January 1994 through December 2014. Of these, 47\% belong to the HS-HS group, $28 \%$ belong to the COL-COL group, $13 \%$ belong to the HS-COL group, and $12 \%$ belong to the COL-HS group.

\subsection{Wages and Retirement Incomes}

In simulating data from the model, I assume that individuals differ not only in gender and education but also in person-type $p_{i}$ that determines the wage $w_{i}=w_{i}\left(p_{i}\right)$. In order to maintain computational feasibility,

\footnotetext{
${ }^{12}$ I focus on this period because the CPS underwent a major redesign in 1994 with changes to the wording of its questionnaire. The redesign has small but significant effects on the measurement of labor force participation by prime-age men and women (Polivka and Miller, 1998).
} 
I assume three person-types: $p_{i} \in\{L, M, H\}$, which generate nine possible household-types characterized by $\left(p_{h}, p_{w}\right) \cdot{ }^{13}$

Because of the assumption that each individual faces an exogenously given degenerate wage offer distribution, the observed joint wage distribution in the simulated data is relatively robust to changes in other model parameters when the employment rate is well matched. To economize on computational costs, I calibrate wage levels $\left\{w_{i}\left(p_{i}\right)\right\}$ and the distribution of $\left(p_{h}, p_{w}\right)$ outside of the estimation procedure to match the means, the standard deviations, and the correlation of the observed joint wage distribution in the CPS. I use the variable "usual weekly earnings" of the CPS as the wage measure. I describe the details of the calibration in Appendix Appendix D.1. As shown in Table 1, the nine household types are evenly distributed: in each group of households, $15 \%$ of the households are of type $\left(p_{h}=M, p_{w}=M\right)$, which is the most common household type.

I determine the levels of retirement income $w_{i}^{r}$ based on a function of wage $w_{i}$ that is similar to the one used by the Social Security Agency in computing retirement incomes. I leave the details of the formula in Appendix Appendix D.2 and display the values of $w_{i}^{r}$ in Table 1.

\subsection{Additional Parametric Assumptions}

In this subsection, I make additional assumptions on model parameters, the values of which are summarized in Table 1.

In the model, the aggregate state $z$ follows a two-state Markov process and affects the baseline job finding rate. I calibrate the transition rates $\pi_{z^{\prime} \mid z}$ using the observed monthly job finding rate of unemployed workers from the CPS. Appendix Appendix D.3 shows the details of the calibration procedure. On average, a Bad state lasts for 3.7 years and a Good state lasts for 6 years.

In the utility function (Eq. 3), $\gamma$ can be interpreted as the coefficient of risk aversion. Following the literature, I set $\gamma=2$. Using the correlation between one spouse's labor market decisions and the other spouse's employment status to identify the risk-aversion parameter, Flabbi and Mabli (2018) estimate the coefficient to be less than 1. However, in their model, households are unable to accumulate wealth in order to insure themselves against income fluctuations. The level of uninsurable risks that households face is likely to be over-estimated, leading to an under-estimation of the degree of risk-aversion.

The $\eta$-shock is a transitory shock to non-employed individuals' ability to conduct job search, which helps explain the observed rate at which unemployed workers leave the labor force. In the CPS, the monthly

\footnotetext{
${ }^{13}$ This already allows for rich heterogeneity in the relative incomes of the spouses in the simulated sample, giving rise to a wide array of household dynamics.
} 
transition rate from unemployment to non-participation is about 0.15 among married women, while it is close to zero among married men. Therefore, I set $\operatorname{Pr}\left(\eta_{w}\right)=0.15$ and $\operatorname{Pr}\left(\eta_{h}\right)=0$. In the simulated data, the $\eta$-shock only accounts for less than $20 \%$ of women's non-participation under plausible parametric assumptions. Some women never participate in the labor force, and others drop out of the labor force immediately following an employment separation.

Since I do not model the capital market, the interest rate $r$ needs to be exogenously set. I assume that the monthly interest rate is 0.002 , which corresponds to an annual rate of 0.024 . Finally, since there is no voluntary job separation in the model, $\delta_{i, z}$ is calibrated to the transition rate from employment to nonemployment based on the CPS.

\subsection{Simulated Method of Moments}

Ten structural parameters remain to be estimated, including four baseline job finding rate parameters, $\left\{\lambda_{i, 0}, \lambda_{i, 1}\right\}_{i=h, w}$, four search disutility function parameters $\left\{\kappa_{i, 0}, \kappa_{i, 1}\right\}_{i=h, w}$, the subjective discount factor $\beta$, and the non-employment income ratio $\mu^{n}$.

The value function in Eq. 4 is invariant to scaling the search intensity choice-set $\boldsymbol{S}$ because combinations of baseline job finding rates and search disutility parameters can always be found with an equivalent effect on the mapping from the job finding rate to search disutility. Therefore, I normalize the set $\boldsymbol{S}$ to be $\{0,0.4,0.8,1.2,1.6,2.0\}$, and choose $\bar{s}$ to be 1 , the median of $\boldsymbol{S}$.

The panel structure of the CPS allows me to construct monthly job finding rates. In the model, an interior job finding rate is the product of the baseline job finding rate and search intensity. Although search intensity per se is not directly observed, the unemployment rate and the labor force participation rate are informative about the fraction of non-employed individuals who are actively searching for work. In the model, the average search intensity is disciplined by $\kappa_{i, 0}$ 's, the scale factors in the search disutility functions. Thus, given $\bar{s}, \kappa_{i, 0}$ 's can be recovered from the labor force participation rate and the unemployment rates of men and women.

$\lambda_{i, 0}$ 's govern the "average" baseline job finding rate and $\lambda_{i, 1}$ 's govern the cyclicality of the baseline job finding rate. They can be recovered from the transition rates into employment of men and women in the two aggregate states.

The difference in the job-finding rate between unemployed workers and non-participants is informative about the dispersion in search intensity. In addition, the variation in labor force moments, including labor force participation rate, the unemployment rate, and the transition rate from non-participation to unemployment, across different spousal employment states is also informative about the extent to which individuals are willing to vary their search intensity. These moments allow me to recover $\kappa_{i, 1}$ 's, which govern the convexity of the search disutility function. A higher $\kappa_{i, 1}$ indicates that the marginal disutility of search increases more 


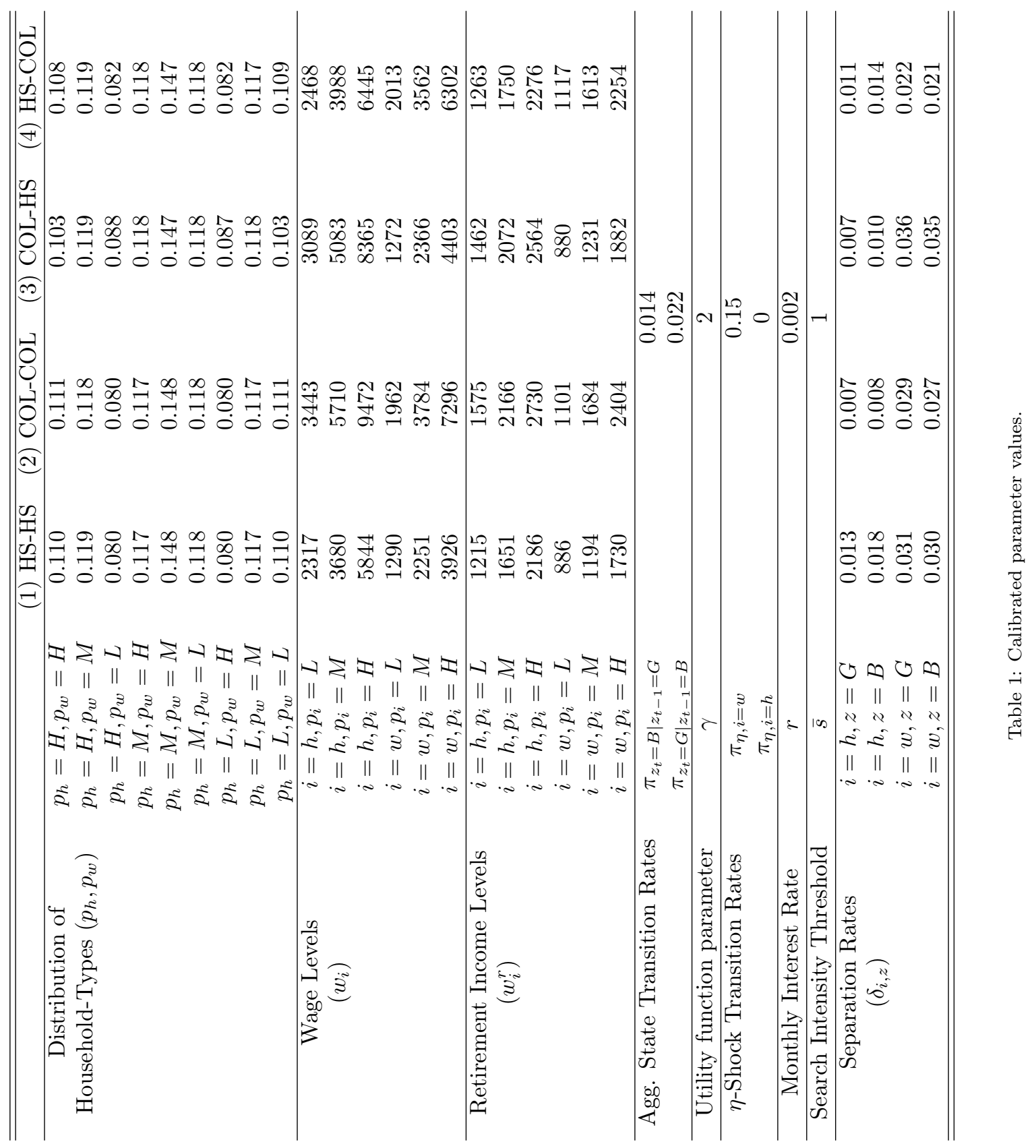


rapidly with search intensity, resulting in less variation in search intensity. The gender-difference in $\kappa_{i, 1}$ 's can be identified as the dispersion in search intensity differs across genders, which is captured by the differences in the above-described moments between men and women.

Gender-asymmetry in search-related parameters, $\lambda_{i, 0}, \lambda_{i, 1}, \kappa_{i, 0}$, and $\kappa_{i, 1}$, is important for fitting various labor market statistics that are specific to each gender and understanding how joint household decision-making affects men and women differently. In Appendix Appendix I, I consider an alternative model in which searchrelated parameters are gender-neutral. I demonstrate that allowing the non-employment income to be gender specific is not sufficient for matching differences in labor force moments between men and women.

The identification of the subjective discount factor $\beta$ requires information on household wealth because $\beta$ disciplines the wealth distribution. Aiyagari (1994) shows that the gap between the interest rate and the subjective discount rate greatly influences households' desire to save. In my model, a lower $\beta$ leads to lower savings. Since the CPS does not contain detailed wealth information, I use data drawn from the Panel Study of Income Dynamics (PSID). I restrict the PSID sample using similar sample restrictions criteria as those described in Section 3.1 and compute the median ratio between lifetime average annual household income and lifetime average household net-worth.

The non-employment income ratio $\mu^{n}$ disciplines consumption fluctuations due to unemployment risk. By studying the spending behavior using data drawn from a large number of checking accounts, Ganong and Noel (2017) find that there is an average of $6 \%$ drop in monthly spending at the onset of unemployment. I target this percentage to identify $\mu^{n}$.

I estimate the structural parameters using the Simulated Method of Moments (SMM). ${ }^{14}$ Given a vector of structural parameters $\theta$, I solve for the optimal savings and job search decisions numerically via backward induction. I discuss the numerical procedure in Appendix Appendix E. Given the optimal decisions, I simulate labor market outcomes, wealth, consumption, and job search behaviors of a sample of married couples. The simulated sample consists of one cohort per year. Each cohort enters the sample at age 25, retires at the end of age 61 , and dies at the end of age 75 . I compute the vector of moments, $\hat{m}(\theta)$, based on simulated couples between 30 and 45 years of age.

The SMM estimator is given by

$$
\hat{\theta}_{S M M}=\arg \min _{\theta}\left(\hat{m}(\theta)-m_{\text {data }}\right)^{T} \hat{W}^{-1}\left(\hat{m}(\theta)-m_{\text {data }}\right)
$$

where $\hat{W}$ is the weighting matrix constructed using the sample variances of the moments as diagonal elements and zeros as off-diagonal elements. I obtain the sample variances of data moments by bootstrapping the

\footnotetext{
${ }^{14}$ Alternatively, a Bayesian-MCMC estimation procedure can be used and has the advantage of producing the exact distribution of the structural parameters. However, the MCMC method is too computationally costly and to be feasible for the task at hand.
} 
data sample 1000 times. Since the objective function is not necessarily smooth in the parameters, I use the gradient-free Nelder-Mead simplex method and reinitiate the Nelder-Mead procedure at the estimated parameter values repeatedly until the estimated values converge.

In summary, the moments include labor force stock and flow moments conditional on the aggregate state, gender, and spousal employment status as well as the rate of drop in consumption at the onset of nonemployment and the median income-to-wealth ratio. The labor force moments include the labor force participation rate, the unemployment rate, and monthly transition rates from unemployment to employment, from non-participation to employment, and from non-participation to unemployment. Appendix Appendix C.2 explains how these moments are computed from the CPS data.

\section{Results and Discussion}

\subsection{Parameter Estimates}

The estimated parameter values are shown in Table 2. Figure F.7 in Appendix Appendix F shows that the objective function reaches a minimum at the estimated parameter values, consistent with the fact that the parameters are well identified

Some observations are worth mentioning. First, the estimated $\kappa_{h, 1}$ is substantially greater than $\kappa_{w, 1}$ in all education groups. Comparing the estimated $k_{h}(\cdot)$ to $k_{w}(\cdot)$, men face lower marginal disutility of search at low search intensity levels, but the disutility increases more rapidly in search intensity. One explanation for is that men's non-working time has more rapidly diminishing marginal value. Another explanation is that men and women choose different job search methods such that the level of search effort required varies differentially in the probability of finding jobs. ${ }^{15} \mathrm{~A}$ third explanation is simply that distaste for job search of men and women vary differentially across search effort levels.

A second observation is that $\lambda_{w, 1}<\lambda_{h, 1}$ in all education groups, which implies that women's job finding rate per unit of search intensity is less cyclical relative to men's. This is consistent with the empirical findings of Hoynes et al. (2012), who find that men are more strongly impacted by recessions and show that the difference in the employment effect of the Great Recession across genders is explained mainly by the industry and occupation of employment.

Differences in the parameter estimates across genders have important implications for the added-worker effect and the comparative advantage effect. In Section 4.3, I examine the differences between job search decisions of men and women.

\footnotetext{
${ }^{15}$ In Appendix Appendix C.1, I document differences in job search methods across genders based on the CPS.
} 


\begin{tabular}{|c|c|c|c|c|c|c|c|c|}
\hline & \multicolumn{2}{|c|}{ (1) HS-HS } & \multicolumn{2}{|c|}{ (2) COL-COL } & \multicolumn{2}{|c|}{ (3) COL-HS } & \multicolumn{2}{|c|}{ (4) HS-COL } \\
\hline & Value & S.E. & Value & S.E. & Value & S.E. & Value & S.E. \\
\hline$\kappa_{h, 0}$ & 0.287 & 0.001 & 0.256 & 0.001 & 0.173 & 0.002 & 0.252 & 0.001 \\
\hline$\kappa_{h, 1}$ & 4.802 & 0.013 & 4.039 & 0.011 & 5.745 & 0.045 & 4.093 & 0.014 \\
\hline$\kappa_{w, 0}$ & 1.633 & 0.002 & 1.872 & 0.003 & 1.741 & 0.004 & 1.413 & 0.004 \\
\hline$\kappa_{w, 1}$ & 1.659 & 0.002 & 1.342 & 0.001 & 1.378 & 0.002 & 1.798 & 0.003 \\
\hline$\lambda_{h, 0}$ & 0.227 & 0.001 & 0.191 & 0.001 & 0.222 & 0.004 & 0.188 & 0.002 \\
\hline$\lambda_{h, 1}$ & 0.088 & 0.002 & 0.053 & 0.002 & 0.074 & 0.003 & 0.078 & 0.003 \\
\hline$\lambda_{w, 0}$ & 0.185 & 0.000 & 0.226 & 0.000 & 0.234 & 0.001 & 0.229 & 0.001 \\
\hline$\lambda_{w, 1}$ & 0.025 & 0.001 & 0.009 & 0.001 & 0.005 & 0.001 & 0.006 & 0.001 \\
\hline$\beta$ & 0.995 & 0.000 & 0.997 & 0.000 & 0.996 & 0.000 & 0.997 & 0.000 \\
\hline$\mu^{n}$ & 0.005 & 0.001 & 0.006 & 0.001 & 0.003 & 0.001 & 0.003 & 0.001 \\
\hline
\end{tabular}

Table 2: Parameter estimates and standard errors.

Notes: $\left\{\kappa_{i, 0}, \kappa_{i, 1}\right\}_{i=h, w}$ are parameters of the search disutility function; $\left\{\lambda_{i, 0}, \lambda_{i, 1}\right\}_{i=h, w}$ are parameters of the baseline job finding rate such that $\lambda_{i, G}=\lambda_{i, 0}+\lambda_{i, 1}$ and $\lambda_{i, B}=\lambda_{i, 0}$ for $i=h, w ; \beta$ is the subjective discount factor; and $\mu^{n}$ is the non-employment income ratio. Standard errors are obtained using the formula of Gourieroux et al. (1993).

\subsection{Goodness of Fit}

\subsubsection{Labor Force Moments}

Tables 3 and 4 show the moments in the SMM estimation for the four groups of households. ${ }^{16}$ The model fits the data well despite a parsimonious parametric specification.

The model well replicates the empirically observed variations in the labor force participation rate, the unemployment rate, and the transition rate from non-participation into unemployment across spousal employment statuses. The patterns indicate that individuals choose higher search intensity when their spouse is unemployment. The model also replicates gender-differences in the gap between the rate at which unemployed workers transition into employment and the rate at which non-participants transition into to employment. The pattern is primarily caused by the differences in the estimated search disutility function between men and women.

The model also generates the pattern that spousal employment is correlated with a higher job finding rate except for the unemployment-to-employment transition rates of women. In the CPS, this correlation is likely to be influenced by the fact that individuals in the same household face similar local labor market conditions. The model does not capture the variations in the baseline job finding rate across local labor markets; instead, the correlation between the job finding rates and spousal employment status results entirely from the addedworker effect and the fact that search decisions of both household members are simultaneously influenced by changes in household wealth. The fact that women's job finding rate is higher when their spouse is unemployment is due to the added-worker effect.

\footnotetext{
${ }^{16}$ The empirical values of the labor force moments are influenced by the way my sample is selected. In Appendix Appendix C.2, I show how the labor force participation rate and the unemployment rate vary with my sample restriction criteria.
} 


\begin{tabular}{|c|c|c|c|c|c|c|c|c|}
\hline & \multicolumn{4}{|c|}{ (1) HS-HS } & \multicolumn{4}{|c|}{ (2) COL-COL } \\
\hline & \multicolumn{2}{|c|}{ Data } & \multicolumn{2}{|c|}{ Model } & \multicolumn{2}{|c|}{ Data } & \multicolumn{2}{|c|}{ Model } \\
\hline & Women & Men & Women & Men & Women & Men & Women & Men \\
\hline \multicolumn{9}{|c|}{ Labor Force Participation Rate (LFPR): } \\
\hline$z=G$, sp. Emp. & 0.794 & 0.986 & 0.787 & 0.984 & 0.754 & 0.984 & 0.748 & 0.986 \\
\hline$z=G$, sp. Unemp. & 0.813 & 0.980 & 0.804 & 0.991 & 0.834 & 0.987 & 0.745 & 0.989 \\
\hline$z=B$, sp. Emp. & 0.782 & 0.979 & 0.773 & 0.973 & 0.757 & 0.981 & 0.760 & 0.977 \\
\hline$z=B$, sp. Unemp. & 0.823 & 0.979 & 0.806 & 0.990 & 0.848 & 0.985 & 0.762 & 0.982 \\
\hline \multicolumn{9}{|c|}{ Unemployment Rate (UR): } \\
\hline$z=G$, sp. Emp. & 0.027 & 0.024 & 0.029 & 0.024 & 0.018 & 0.013 & 0.020 & 0.015 \\
\hline$z=G$, sp. Unemp. & 0.095 & 0.086 & 0.093 & 0.079 & 0.068 & 0.049 & 0.065 & 0.049 \\
\hline$z=B$, sp. Emp. & 0.040 & 0.045 & 0.032 & 0.042 & 0.026 & 0.022 & 0.021 & 0.020 \\
\hline$z=B$, sp. Unemp. & 0.134 & 0.147 & 0.117 & 0.151 & 0.084 & 0.071 & 0.083 & 0.080 \\
\hline \multicolumn{9}{|c|}{ Unemployment-to-Employment Transition Rate (U-to-E): } \\
\hline$z=G$, sp. Emp. & 0.311 & 0.346 & 0.223 & 0.382 & 0.340 & 0.319 & 0.248 & 0.297 \\
\hline$z=G$, sp. Unemp. & 0.236 & 0.278 & 0.226 & 0.219 & 0.226 & 0.233 & 0.262 & 0.165 \\
\hline$z=B$, sp. Emp. & 0.213 & 0.247 & 0.197 & 0.275 & 0.254 & 0.221 & 0.240 & 0.232 \\
\hline$z=B$, sp. Unemp. & 0.144 & 0.171 & 0.212 & 0.139 & 0.226 & 0.175 & 0.254 & 0.113 \\
\hline \multicolumn{9}{|c|}{ Non-Participation-to-Employment Transition Rate (N-to-E): } \\
\hline$z=G$, sp. Emp. & 0.079 & 0.263 & 0.087 & 0.254 & 0.067 & 0.190 & 0.070 & 0.196 \\
\hline$z=G$, sp. Unemp. & 0.072 & 0.229 & 0.074 & 0.186 & 0.063 & 0.212 & 0.065 & 0.137 \\
\hline$z=B$, sp. Emp. & 0.066 & 0.190 & 0.074 & 0.182 & 0.060 & 0.172 & 0.068 & 0.153 \\
\hline$z=B$, sp. Unemp. & 0.061 & 0.230 & 0.060 & 0.114 & 0.071 & 0.259 & 0.062 & 0.093 \\
\hline \multicolumn{9}{|c|}{ Non-Participation-to-Unemployment Transition Rate (N-to-U): } \\
\hline$z=G$, sp. Emp. & 0.019 & 0.098 & 0.026 & 0.032 & 0.011 & 0.049 & 0.015 & 0.021 \\
\hline$z=G$, sp. Unemp. & 0.075 & 0.234 & 0.142 & 0.203 & 0.070 & 0.166 & 0.071 & 0.172 \\
\hline$z=B$, sp. Emp. & 0.023 & 0.120 & 0.025 & 0.035 & 0.013 & 0.073 & 0.016 & 0.023 \\
\hline$z=B$, sp. Unemp. & 0.090 & 0.286 & 0.165 & 0.313 & 0.073 & 0.229 & 0.091 & 0.168 \\
\hline Drop in consumption: & \multicolumn{2}{|c|}{0.060} & \multicolumn{2}{|c|}{0.082} & \multicolumn{2}{|c|}{0.060} & \multicolumn{2}{|c|}{0.039} \\
\hline Inc.-wealth ratio: & \multicolumn{2}{|c|}{1.017} & \multicolumn{2}{|c|}{2.042} & \multicolumn{2}{|c|}{0.644} & \multicolumn{2}{|c|}{1.214} \\
\hline
\end{tabular}

Table 3: Data and simulated moments in the SMM estimation (HS-HS and COL-COL households)

Notes: "Data" columns show moments computed from the sample of married couples drawn from the matched monthly CPS data. "Model" columns show moments computed from data simulated from the model given parameter estimates in Table 2. Labor force moments are conditional on the aggregate state and the spouse's labor force status (employed or unemployed). "Inc.-Wealth Ratio" is the median ratio of lifetime average annual income to lifetime average wealth. "Consumption Drop" is the rate of drop in consumption at the onset of non-employment. 


\begin{tabular}{|c|c|c|c|c|c|c|c|c|}
\hline & \multicolumn{4}{|c|}{ (1) COL-HS } & \multicolumn{4}{|c|}{ (2) HS-COL } \\
\hline & \multirow{2}{*}{$\begin{array}{c}\text { Data } \\
\text { Women }\end{array}$} & \multirow{2}{*}{ Men } & \multirow{2}{*}{$\begin{array}{c}\text { Model } \\
\text { Women }\end{array}$} & \multirow[b]{2}{*}{ Men } & \multirow{2}{*}{$\begin{array}{c}\text { Data } \\
\text { Women }\end{array}$} & \multirow{2}{*}{\multicolumn{2}{|c|}{$\begin{array}{cc} & \text { Model } \\
\text { Men } & \text { Women }\end{array}$}} & \multirow[b]{2}{*}{ Men } \\
\hline & & & & & & & & \\
\hline \multicolumn{9}{|c|}{ Labor Force Participation Rate (LFPR): } \\
\hline$z=G$, sp. Emp. & 0.704 & 0.990 & 0.693 & 0.992 & 0.880 & 0.978 & 0.869 & 0.984 \\
\hline$z=G$, sp. Unemp. & 0.756 & 0.990 & 0.691 & 0.992 & 0.918 & 0.982 & 0.878 & 0.992 \\
\hline$z=B$, sp. Emp. & 0.689 & 0.988 & 0.702 & 0.986 & 0.878 & 0.970 & 0.874 & 0.965 \\
\hline$z=B$, sp. Unemp. & 0.798 & 0.987 & 0.718 & 0.988 & 0.921 & 0.980 & 0.882 & 0.980 \\
\hline \multicolumn{9}{|c|}{ Unemployment Rate (UR): } \\
\hline$z=G$, sp. Emp. & 0.024 & 0.014 & 0.026 & 0.015 & 0.017 & 0.019 & 0.019 & 0.023 \\
\hline$z=G$, sp. Unemp. & 0.084 & 0.050 & 0.080 & 0.048 & 0.052 & 0.059 & 0.043 & 0.053 \\
\hline$z=B$, sp. Emp. & 0.037 & 0.027 & 0.028 & 0.027 & 0.025 & 0.037 & 0.020 & 0.034 \\
\hline$z=B$, sp. Unemp. & 0.113 & 0.085 & 0.088 & 0.084 & 0.066 & 0.097 & 0.059 & 0.099 \\
\hline \multicolumn{9}{|c|}{ Unemployment-to-Employment Transition Rate (U-to-E): } \\
\hline$z=G$, sp. Emp. & 0.339 & 0.326 & 0.254 & 0.357 & 0.323 & 0.355 & 0.243 & 0.321 \\
\hline$z=G$, sp. Unemp. & 0.185 & 0.212 & 0.275 & 0.177 & 0.199 & 0.282 & 0.240 & 0.234 \\
\hline$z=B$, sp. Emp. & 0.225 & 0.233 & 0.250 & 0.268 & 0.251 & 0.233 & 0.238 & 0.227 \\
\hline$z=B$, sp. Unemp. & 0.179 & 0.102 & 0.291 & 0.118 & 0.171 & 0.218 & 0.224 & 0.146 \\
\hline \multicolumn{9}{|c|}{ Non-Participation-to-Employment Transition Rate (N-to-E): } \\
\hline$z=G$, sp. Emp. & 0.063 & 0.251 & 0.064 & 0.238 & 0.108 & 0.167 & 0.109 & 0.213 \\
\hline$z=G$, sp. Unemp. & 0.044 & 0.375 & 0.055 & 0.196 & 0.181 & 0.106 & 0.098 & 0.163 \\
\hline$z=B$, sp. Emp. & 0.053 & 0.269 & 0.062 & 0.177 & 0.093 & 0.153 & 0.106 & 0.150 \\
\hline$z=B$, sp. Unemp. & 0.084 & 0.281 & 0.056 & 0.160 & 0.080 & 0.244 & 0.090 & 0.089 \\
\hline \multicolumn{9}{|c|}{ Non-Participation-to-Unemployment Transition Rate (N-to-U): } \\
\hline$z=G$, sp. Emp. & 0.011 & 0.082 & 0.013 & 0.028 & 0.019 & 0.073 & 0.030 & 0.012 \\
\hline$z=G$, sp. Unemp. & 0.067 & 0.300 & 0.071 & 0.171 & 0.086 & 0.245 & 0.099 & 0.123 \\
\hline$z=B$, sp. Emp. & 0.014 & 0.122 & 0.015 & 0.031 & 0.023 & 0.068 & 0.031 & 0.022 \\
\hline$z=B$, sp. Unemp. & 0.069 & 0.242 & 0.081 & 0.164 & 0.076 & 0.221 & 0.125 & 0.237 \\
\hline Drop in Consumption: & \multicolumn{2}{|c|}{0.060} & \multicolumn{2}{|c|}{0.044} & \multicolumn{2}{|c|}{0.060} & \multicolumn{2}{|c|}{0.039} \\
\hline Inc.-Wealth Ratio: & \multicolumn{2}{|c|}{0.680} & \multicolumn{2}{|c|}{1.459} & \multicolumn{2}{|c|}{0.762} & \multicolumn{2}{|c|}{1.124} \\
\hline
\end{tabular}

Table 4: Data and simulated moments in the SMM estimation (COL-HS and HS-COL households) See notes in Table 3. 
Conditional on spousal labor force status, the model matches the weak cyclicality in the labor force participation rate, the counter-cyclicality in the unemployment rate, and the cyclicality in the non-participationto-unemployment transition rate. Table 5 shows the average values of the labor force moments by aggregate state. Relative to the moments conditional on spousal employment status, the unconditional moments are additionally influenced by cyclical fluctuations in the employment rate of the spouse. Although the moments in Table 5 are not targeted in the SMM estimation, the model performs well in matching the cyclical patterns.

The only exception is that the cyclicality of women's unemployment rate is underestimated. One explanation is that the cyclicality of the unemployment rate is influenced by the extensions of Unemployment Insurance (UI) benefits during periods of high unemployment rates, which disincentivize unemployed workers from becoming reemployed or inactive. Rothstein (2011) show that UI extensions in the Great Recession cause a one percentage point decrease in women's reemployment rate. Also driving the cyclical fluctuations in the unemployment exit rate is the composition of unemployed workers' labor force attachment. Elsby et al. (2015) find that, during recessions, unemployed workers are, on average, less likely to drop out of the labor force because they are more likely to be laid off by a previous employer.

Since the model does not account for cyclical UI extensions or endogenous lay-off decisions, it is difficult to replicate the cyclical variations in the unemployment exit rate shown in the data. However, it should be noted that these factors are not unique to married couples and, thus, conclusions drawn from the comparison between simulated married and single individuals is likely to remain valid even if the model were extended to include the factors in question.

\subsubsection{Consumption and Wealth Moments}

The bottom part of Tables 3 and 4 give the consumption and wealth moments. The rate of drop in consumption is computed as the percentage decrease in consumption at the onset of non-employment of a household member. The target consumption drop is taken from Ganong and Noel (2017), which is $6 \%$. In the simulated data, there are moderate variations across groups of households: HS-HS households experience the largest drop of $8 \%$, while other groups of households experience a consumption drop of around $4 \%$. Even though the model does not have a UI system, it is still able to match the magnitude of consumption fluctuations because unemployment risk is the only type of risk that households in the model face.

The last moment, income-to-wealth ratio, is the median ratio of average annual household income to average household wealth. The target moment is computed from the PSID using household net worth. The simulated median income-to-wealth ratio is higher than that computed from the PSID, which may cause concerns that the model exaggerates the role of joint decision-making as a self-insurance mechanism. Figure 1 shows the simulated wealth distributions and the distributions of household net worth in the PSID. It is clear from the figure that the model is unable to match the fat right tail of the wealth distribution, a known difficulty for 


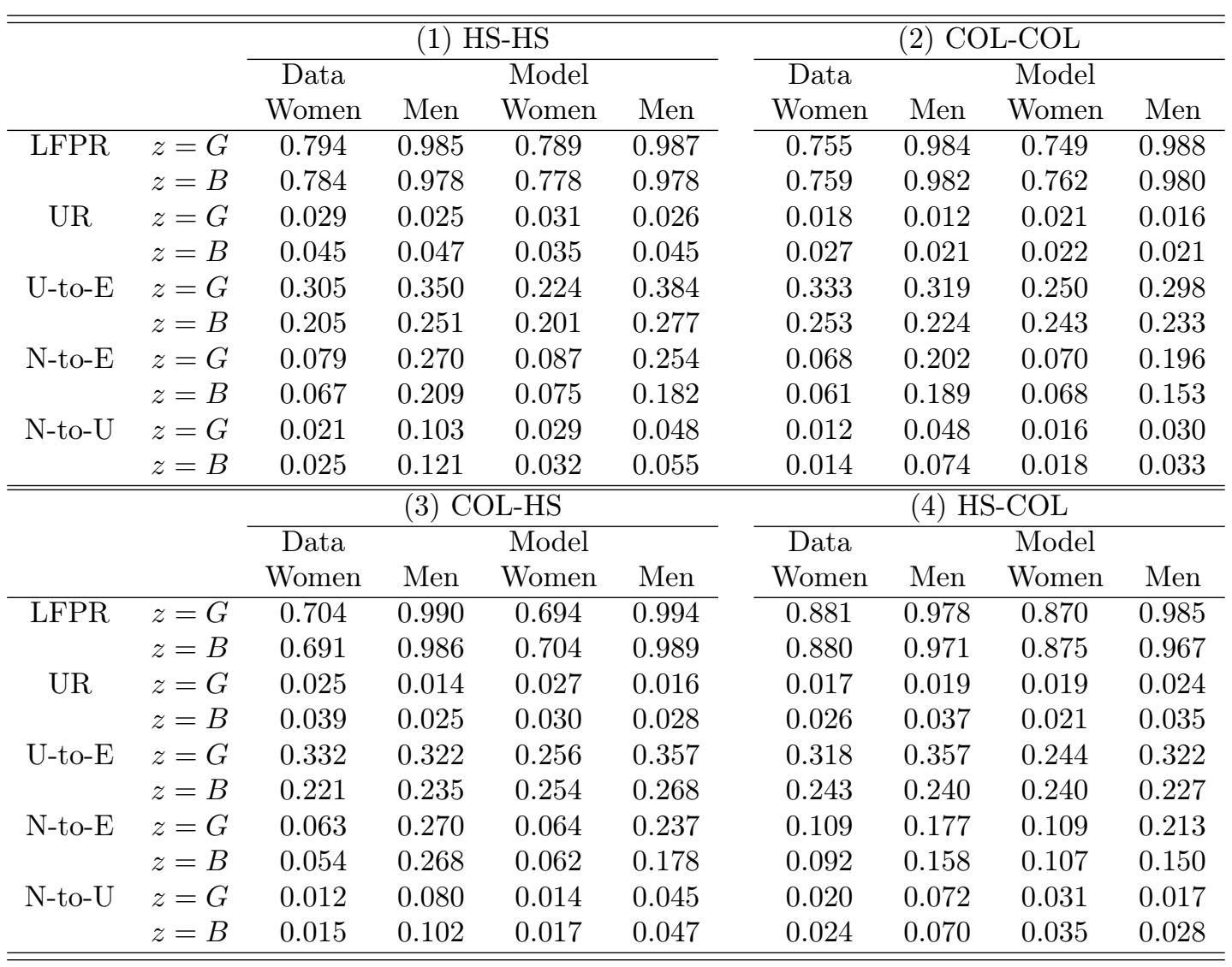

Table 5: Labor force moments by aggregate state.

Notes: "Data" columns show moments computed from the sample of married couples drawn from the matched monthly CPS data. "Model" columns show moments computed from data simulated from the model given parameter estimates in Table 2. 
models with only unemployment risk. This helps explain the model's overestimation of the income-to-wealth ratio.

To ensure that the model does not exaggerate household self-insurance, the model should not over-estimate the fraction of households that are credit constrained. Figure 1 also shows the distribution of net wealth excluding home equity in the PSID. In the literature, negative and zero non-equity net wealth is often used as an indicator for credit constrained households. Based on this measure, the shares of credit constrained married-couple households in the 1999 PSID sample are 13.4\% (HS-HS), 9.8\% (COL-COL), 8.9\% (COL-HS), and $6.2 \%$ (HS-COL). In the simulated data, the corresponding wealth percentiles are equal to approximately four times the monthly wage $w_{h}\left(p_{h=M}\right)$, suggesting that relatively few households in the model are close to the borrowing constraint.

\subsection{The Search Intensity Decision}

In this Subsection, I examine how the optimal search intensity in the estimated model varies with wealth, the aggregate state, and spousal employment status.

Figure 2 illustrates how the optimal search intensity depends on the aggregate state. Overall, women's search intensity is more responsive to changes in the aggregate state, which is attributable to the difference between the estimated $\kappa_{h, 1}$ and $\kappa_{w, 1}$. More importantly, both the level and the cyclicality of search intensity are correlated with wealth. As explained in Section 2, search intensity decreases in wealth due to the assumption of decreasing marginal utility and the additive separability of utility of consumption and disutility of search effort. The relationship between the cyclicality of search intensity and wealth is due to the wealth effect: In a Bad aggregate state, those from wealth-poor households are more likely to increase search intensity rather than decrease consumption in order to smooth consumption. The comparative advantage effect also contributes to the counter-cyclicality in women's optimal search intensity. Since $\lambda_{1, h}>\lambda_{1, w}$, women face a less cyclical baseline job finding rate and thus have greater incentives to increase search intensity in the Bad state.

To understand the implications for the cyclicality of the unemployment rate, consider three groups of job searchers. The first group consists of intensive searchers who are always classified as unemployed workers. In this group, counter-cyclical search intensity leads to a counter-cyclical job finding rate. The second group consists of those whose search intensity fluctuates around $\bar{s}$, whom I refer to as marginally attached workers. With counter-cyclical search intensity, a greater fraction of marginally attached workers are classified into unemployment in the Bad state. The last group consists of mild job searchers who are always classified as nonparticipants. They are most likely to search pro-cyclically, which makes the non-participation-to-employment transition rate more pro-cyclical. 


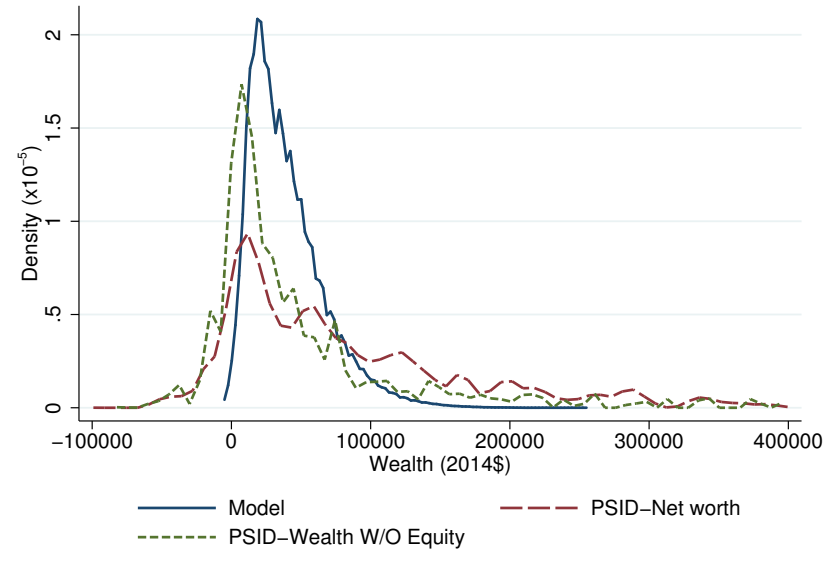

(a) HS-HS

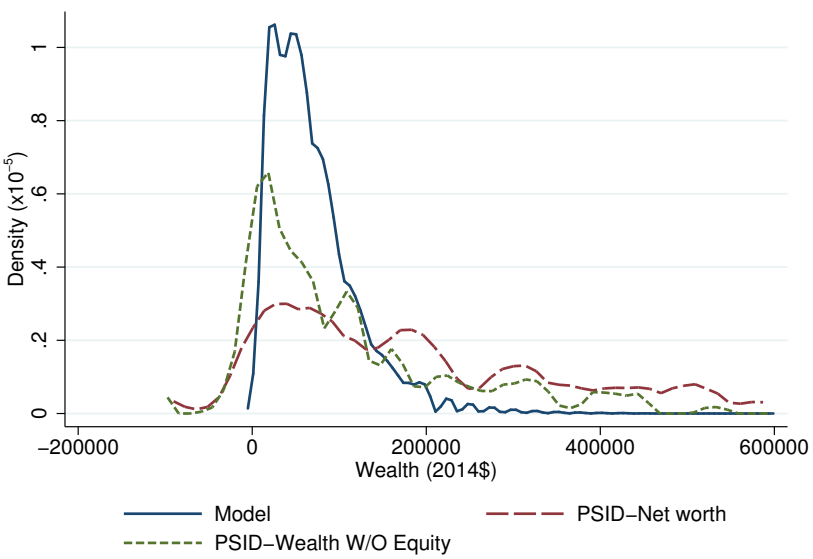

(c) COL-HS

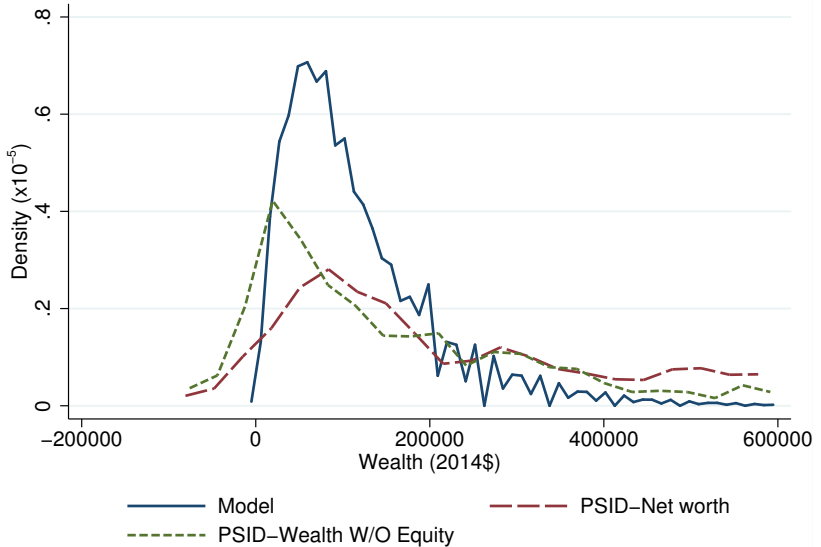

(b) COL-COL

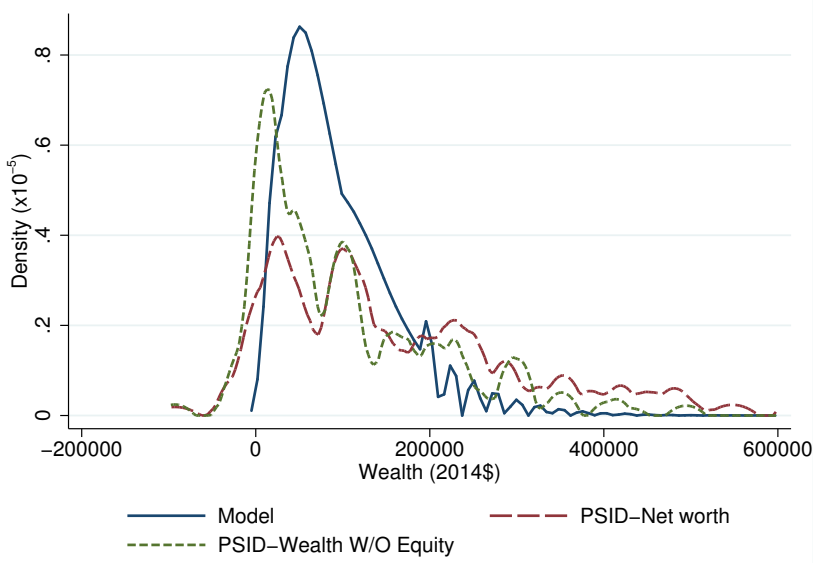

(d) HS-COL

Figure 1: Model fit of wealth distribution.

Notes: The graphs show wealth distributions based on the simulated data and the PSID in 1999. In the PSID, "net worth" is household net wealth, and "Wealth W/O Equity" is household net wealth excluding equity in own home. PSID wealth distributions are based on a sample married-couple households. 

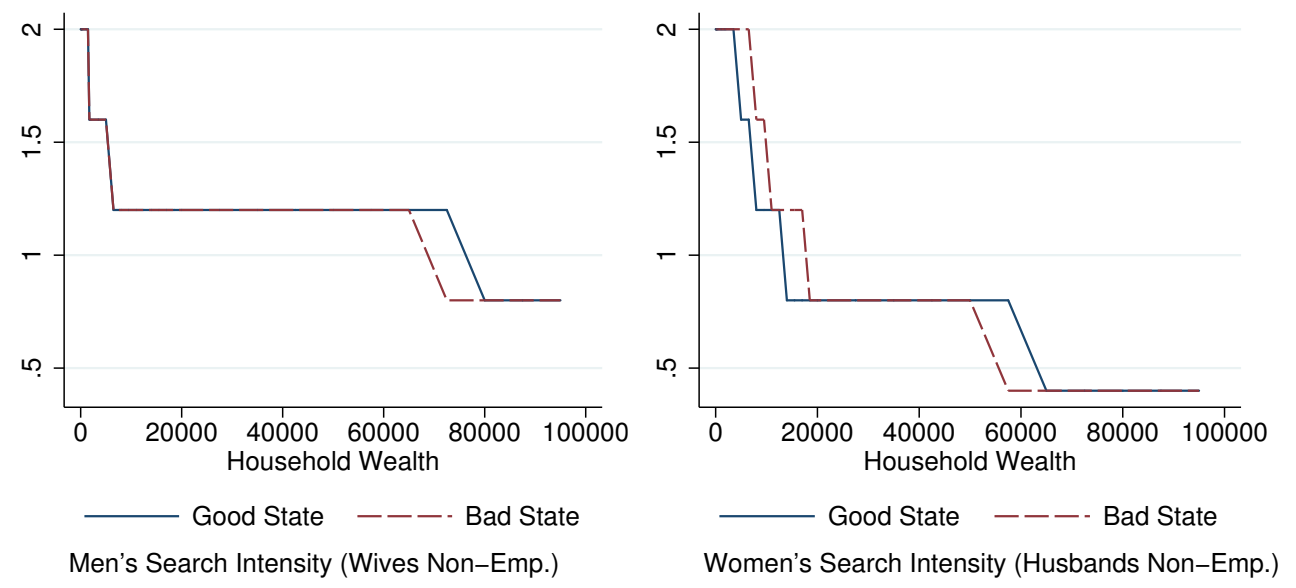

Figure 2: Optimal search intensity of men and women by aggregate state.

Notes: The graphs show the optimal search intensity computed for a HS-HS couple of type $\left(p_{h}=M, p_{l}=M\right)$ at age 35 conditional on spousal non-employment. The optimal search intensity is solved from the model given parameter estimates in Table 2.

Going beyond the binary job search has ramifications for the degrees of cyclicality associated with the unemployment rate and the labor force participation rate because a binary job search decision is not able to capture the cyclical fluctuations in search intensity of intensive and mild searchers. The difference across genders displayed in Figure 2 suggests that cyclical fluctuations in women's labor force moments are particularly difficult to match for a binary search model. In Appendix Appendix H, I estimate the alternative model in which there are only binary search decisions and show that the model generates counterfactual cyclicality in women's labor force participation rate.

Figure 3 illustrates how the optimal search intensity depends on spousal employment status. Overall, the optimal search intensity rises with spousal employment. There is also stark gender-asymmetry: Women's search intensity is more responsive to changes in spousal employment status, implying that the added-worker effect is likely to play a more important role in fluctuations of women's unemployment rate.

\section{Does Joint Decision-Making Matter?}

Joint decision-making by couples can affect the unemployment rate over the business cycle; it is also a selfinsurance mechanism as it allows spouses to share risks with one another. In order to quantify these effects, I consider a counterfactual individualist model and compare simulated data generated from the baseline married-couple model to those generated from the counterfactual model. 


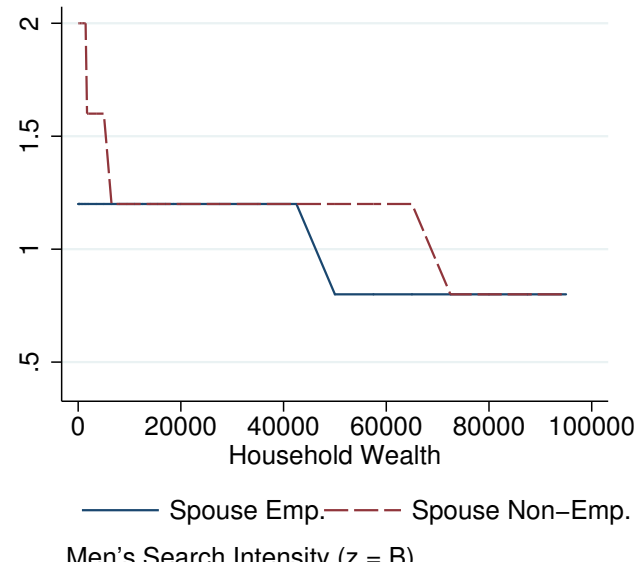

Men's Search Intensity $(z=B)$

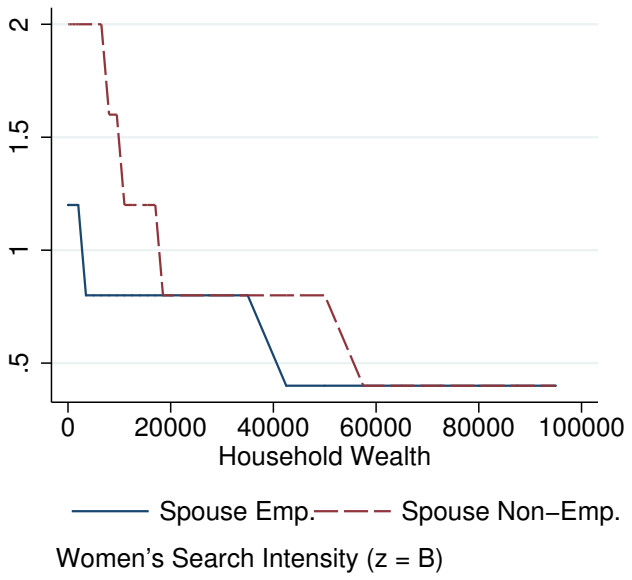

Figure 3: Optimal search intensity decision by spousal employment status.

Notes: The graphs show the optimal search intensity computed for a HS-HS couple of type $\left(p_{h}=M, p_{l}=M\right)$ at age 35 conditional on $z=B$. The optimal search intensity is solved from the model given parameter estimates in Table 2.

\subsection{Counterfactual Individualist Household Model}

In the individualist model, household members behave like single individuals, making their own consumption and search decisions and facing their own budget constraints. Each household consists of an individualist female, indexed by $i=w$, and an individualist male, indexed by $i=h$.

In the working stage, the present value of household member $i \in\{h, w\}$ in period $\tau \leq \tau_{\text {work }}$ is

$$
V_{\tau, i}(a, l, z, \eta)=\max _{c, s}\left\{u(c)-k_{i}(s)+\beta \mathbf{E} V_{\tau+1, i}\left(a^{\prime}, l^{\prime}, z^{\prime}, \eta^{\prime}\right)\right\}
$$

subject to

$$
\begin{gathered}
s \in S(l, \eta) \\
0 \leq a^{\prime} \leq(1+r) a+\left[w_{i} l+w_{i}^{n}(1-l)\right]-c,
\end{gathered}
$$

where $a, l$, and $\eta$ are $i$ 's own wealth, employment status, and state of the $\eta$-shock, respectively. The expectation is taken over $\left\{l^{\prime}, z^{\prime}, \eta^{\prime}\right\}$ such that

$$
\begin{aligned}
\operatorname{Pr}\left(l^{\prime}=1 \mid l=0\right) & =\lambda\left(s_{i}, \lambda_{i, z}\right) ; \\
\operatorname{Pr}\left(l_{i}^{\prime}=0 \mid l_{i}=1\right) & =\delta_{i, z} ; \\
\operatorname{Pr}\left(\eta_{i}^{\prime}=1 \mid \eta_{i}=0\right) & =\pi_{\eta, i} ; \\
\operatorname{Pr}\left(\eta_{i}^{\prime}=0 \mid \eta_{i}=1\right) & =1 ; \\
\operatorname{Pr}\left(z^{\prime} \mid z\right) & =\pi_{z^{\prime} \mid z} \text { for } z^{\prime}=G, B .
\end{aligned}
$$

The functions $k_{i}(\cdot)$ and $u(\cdot)$ are defined in Eq. 2 and 3, respectively. 
In the retirement stage, the present value of household member $i \in\{h, w\}$ in period $\tau$ such that $\tau_{\text {work }}<\tau \leq$ $\tau_{w o r k}+\tau_{r e t}$ is

$$
V_{\tau, i}(a, l, z, \eta)=V_{\tau, i}^{R}(a)=\max _{c}\left\{u(c)+\beta V_{\tau+1, i}^{R}\left(a^{\prime}\right)\right\}
$$

subject to

$$
0 \leq a^{\prime} \leq(1+r) a+w_{i}^{r}-c .
$$

As with the baseline model, the individualist model can be solved by backward induction separately for each household member. Given the parameter values in Tables 1 and 2, I solve for the optimal decisions and generate simulated data in the same fashion as described in Section 3.4 using the same set of idiosyncratic and aggregate shocks.

\subsection{Cyclicality of the Unemployment Rates}

Columns (1) and (2) of Table 6 show the simulated unemployment rate in each aggregate state. Simulated individualist women have a higher unemployment rate than simulated married women; the opposite is true for men. The gender difference stems from household specialization: In the baseline model, there is a transfer of consumption from husbands to wives, especially in households in which the wife does not have a college degree.

The counter-cyclicality of the simulated unemployment rate is measured both as an absolute difference and a relative difference between the two aggregate states, which are shown in Columns (3) and (4) of Table 6 respectively. The effect of joint decision-making on the cyclicality of the unemployment rate is also genderasymmetric. The simulated unemployment rate of individualist women is pro-cyclical, but that of married women is counter-cyclical. The difference is greater in the HS-HS and the COL-HS groups, implying that, for married women, less education gives rise to job search decisions that are more dependent on cyclical fluctuations of the husband's employment outcome or prospects.

In contrast to women, men's unemployment rate displays strong counter-cyclicality in both the marriedcouple model and the individualist model. There is no clear indication that joint decision-making amplifies or attenuates the cyclicality of men's unemployment rate. Based on the relative measure of counter-cyclicality shown in Column (4) of the Table 6, individualist men's unemployment rate is more counter-cyclical compared to that of married men. However, the absolute measure of counter-cyclicality in Column (3) indicates that this is true only among the simulated HS-COL households; among other simulated households, the unemployment rate of individualist men is less or equally counter-cyclical as that of married men.

The difference across genders can be attributed to the added-worker effect and the comparative advantage effect, both of which affect men and women differently. As explained in Section 4.3, women's search intensity is more responsive to changes in spousal employment status, suggesting a stronger added-worker effect. In 
addition, the estimation result that $\lambda_{1, h}>\lambda_{1, w}$ implies that married women have counter-cyclical comparative advantage in the labor market, incentivizing them to choose counter-cyclical search intensity.

\subsection{Welfare Cost of Cyclical Fluctuations}

Cyclical fluctuations are costly to households that are risk-averse and imperfectly insured. As a household selfinsurance mechanism, spouses share risks with one another by pooling their incomes and coordinating their search decisions. In this subsection, I compare the simulated welfare cost of cyclical fluctuations experienced by married-couple households to that experienced by individualist households.

To measure the household welfare level, I compute the sum of consumption-equivalents of household members' lifetime utilities. More specifically, I define the household consumption-equivalent $\bar{c}$ as

$$
\bar{c}=\sum_{i=h, w} u^{-1}\left(\frac{\sum_{\tau=1}^{\tau_{\text {work }}+\tau_{\text {ret }}}\left[u\left(c_{i, \tau}\right)-\kappa_{i}\left(s_{i, \tau}\right)\right]}{\tau_{\text {work }}+\tau_{\text {ret }}}\right),
$$

where $c_{i, \tau}$ and $s_{i, \tau}$ are the simulated consumption and search intensity of household member $i$ in period $\tau$. The welfare cost of cyclical fluctuations is computed as the percentage increase in welfare if there were no cyclical fluctuations in the labor market. ${ }^{17}$ In the a-cyclical environment, the baseline job finding rate and the separation rate are time-invariant, the levels of which are the averages weighed by the stationary distribution of the Markov process of $z$.

As seen from Table 7, the average welfare cost of cyclical fluctuations experienced by married-couple households varies from $0.9 \%$ among HS-HS households to $0.2 \%$ among COL-COL households. The values are in line with the literature. For example, Krebs (2007) find that with a coefficient of risk-aversion of 2, the cost of business cycles is $0.98 \%$ of the lifetime consumption. ${ }^{18}$ The welfare cost of cyclical fluctuations experienced by individualist households is, on average, $1 / 3$ to $1 / 2$ times higher than that experienced by married-couple households, suggesting that joint decision-making is an effective way to insure against cyclical fluctuations in the labor market.

There is a large variation in the welfare cost of cyclical fluctuations across households. Households at the lower end of the welfare distribution experience a higher cost of cyclical fluctuations because they are unable to accumulate wealth to insure themselves against cyclical shocks due to lower potential wages or bad luck. Except in the COL-COL model, joint decision-making is particularly important for the households at the bottom of the welfare distribution. The result complements Ortigueira and Siassi (2013), who find that

\footnotetext{
${ }^{17}$ This way of measuring the cost of cyclical fluctuations follows Lucas Jr. (1987).

${ }^{18}$ It should be noted that there are significant differences between the model in Krebs (2007) and the model in this paper. In Krebs (2007), the aggregate state affects the likelihood of job displacements instead of the job finding rate, and the income shock associated with a job displacement is permanent. In addition, the unit of decision is an individual, and there is no job search decision.
} 


\begin{tabular}{cccccc}
\hline \hline & & $(1) U R_{G}$ & $(2) U R_{B}$ & $(3) U R_{B}-U R_{G}$ & $(4)\left(U R_{B}-U R_{G}\right) / U R_{G}$ \\
\hline \multirow{2}{*}{ Women } & Married & 0.031 & 0.035 & 0.005 & $15.0 \%$ \\
& Individualist & 0.085 & 0.085 & 0.000 & $0.0 \%$ \\
\hline \multirow{2}{*}{ Men } & Married & 0.026 & 0.045 & 0.019 & $74.4 \%$ \\
& Individualist & 0.018 & 0.035 & 0.017 & $95.6 \%$ \\
\hline \hline
\end{tabular}

(a) HS-HS

\begin{tabular}{cccccc}
\hline \hline \multirow{2}{*}{ Women } & & $(1) U R_{G}$ & $(2) U R_{B}$ & $(3) U R_{B}-U R_{G}$ & $(4)\left(U R_{B}-U R_{G}\right) / U R_{G}$ \\
& Married & 0.021 & 0.022 & 0.001 & $4.8 \%$ \\
& Individualist & 0.059 & 0.056 & -0.003 & $-5.1 \%$ \\
\hline \multirow{2}{*}{ Men } & Married & 0.016 & 0.021 & 0.005 & $33.4 \%$ \\
& Individualist & 0.010 & 0.016 & 0.005 & $73.5 \%$ \\
\hline \hline
\end{tabular}

(b) COL-COL

\begin{tabular}{cccccc}
\hline \hline & & $(1) U R_{G}$ & $(2) U R_{B}$ & $(3) U R_{B}-U R_{G}$ & $(4)\left(U R_{B}-U R_{G}\right) / U R_{G}$ \\
\hline \multirow{2}{*}{ Women } & Married & 0.027 & 0.030 & 0.003 & $11.8 \%$ \\
& Individualist & 0.084 & 0.082 & -0.002 & $-2.4 \%$ \\
\hline \multirow{2}{*}{ Men } & Married & 0.016 & 0.028 & 0.012 & $75.8 \%$ \\
& Individualist & 0.009 & 0.017 & 0.008 & $88.0 \%$ \\
\hline \hline
\end{tabular}

(c) COL-HS

\begin{tabular}{cccccc}
\hline \hline \multirow{2}{*}{ Women } & & $(1) U R_{G}$ & $(2) U R_{B}$ & $(3) U R_{B}-U R_{G}$ & $(4)\left(U R_{B}-U R_{G}\right) / U R_{G}$ \\
& Married & 0.019 & 0.021 & 0.002 & $8.3 \%$ \\
& Individualist & 0.039 & 0.038 & -0.001 & $-2.2 \%$ \\
\hline \multirow{2}{*}{ Men } & Married & 0.024 & 0.035 & 0.012 & $49.3 \%$ \\
& Individualist & 0.021 & 0.036 & 0.015 & $73.0 \%$ \\
\hline \hline
\end{tabular}

(d) HS-COL

Table 6: Cyclicality of the unemployment rate in simulated data.

Notes: The tables show the levels and counter-cyclicality of the simulated unemployment rate. Married women and men are simulated individuals from the baseline married-couple model, while individualist women and men are individuals simulated from the counterfactual individualist model. Columns (1) and (2) show the unemployment rate in each aggregate state. Columns (3) and (4) show, respectively, absolute and percentage increases in the unemployment rate from the Good state to the Bad state. 
wealth-poor households rely most heavily on spousal labor supply to insure against idiosyncratic employment risks.

Naturally, married couples may also face other constraints. For example, Guler et al. (2012) consider a model in which couples face the cost of living in separate locations. However, although couples' location constraints may lower the average benefit of joint decision-making, they are unlikely to affect the benefit of joint decisionmaking in reducing the welfare cost of cyclical fluctuations. In the simulated data from my baseline model, the share of dual-employment couples varies pro-cyclically. In addition, empirical studies show that the benefit of moving is pro-cyclical (Saks and Wozniak, 2011). The evidence suggests that the location constraint is more likely to be binding in the Good state rather than in the Bad state, which implies that the constraint does not weaken the ability for joint decision-making to insure against cyclical fluctuations.

\section{Conclusion}

As previous literature such as Guler et al. (2012) has shown, when couples are risk-averse and imperfectly insured, interactions between spouses can lead to labor market behaviors that are significantly different from those of singles. In this paper, I find that, in the presence of aggregate shocks in the labor market, joint decision-making by couples has implications for the cyclicality of search effort and the welfare cost of cyclical fluctuations.

I consider a life-cycle model of married couples that face idiosyncratic and aggregate shocks and seek to insure themselves by making joint consumption and job search decisions. Joint decision-making influences the cyclicality of search intensity through two main mechanisms. The first is the added-worker effect, which arises as individuals search for employment more intensively when their spouse is non-employed. Since non-employment is counter-cyclical in the data, the added-worker effect contributes to the counter-cyclical fluctuations in search intensity. The second is the comparative advantage effect, which arises since the job finding rate per unit of search intensity can vary differentially for men and women over the business cycle. For the spouse facing less cyclicality, the comparative advantage effect amplifies the counter-cyclicality of his or her search intensity.

Given the observed heterogeneity in labor force attachment among non-employed workers, I assume a multilevel search intensity decision and use a threshold rule to classify non-employed individuals as unemployed workers or non-participants. The cyclicality of search intensity has intricate implications for the unemployment rate because search intensity both affects the job finding rate and determines if a non-employed individual is classified as an unemployed worker.

I estimate the model based on a sample of married couples from the CPS. The results show gender-asymmetry: Women's optimal search intensity is more responsive to changes in the aggregate state and in spousal employment status, while their job finding rate per unit of search intensity is less cyclical than men's. 


\begin{tabular}{cccccc}
\hline \hline & \multicolumn{2}{c}{ Married-Couple Households } & & \multicolumn{2}{c}{ Individualist Households } \\
\cline { 2 - 3 } \cline { 5 - 6 } Welfare Percentile & $\bar{c}_{c y c}$ & Cost of Cyc. & & $\bar{c}_{c y c}$ & Cost of Cyc. \\
\hline Bottom 10\% & 2713 & $1.7 \%$ & & 1754 & $2.4 \%$ \\
$10-50 \%$ & 3961 & $1.1 \%$ & & 3543 & $1.6 \%$ \\
Top 50\% & 6053 & $0.6 \%$ & & 5756 & $0.7 \%$ \\
\hline Overall & 4882 & $0.9 \%$ & & 4471 & $1.2 \%$ \\
\hline \hline
\end{tabular}

(a) HS-HS

\begin{tabular}{cccccc}
\hline \hline & \multicolumn{2}{c}{ Married-Couple Households } & & \multicolumn{2}{c}{ Individualist Households } \\
\cline { 2 - 3 } \cline { 5 - 6 } Welfare Percentile & $\bar{c}_{c y c}$ & Cost of Cyc. & & $\bar{c}_{c y c}$ & Cost of Cyc. \\
\hline Bottom 10\% & 4029 & $0.8 \%$ & & 3041 & $1.0 \%$ \\
$10-50 \%$ & 6206 & $0.3 \%$ & & 5652 & $0.5 \%$ \\
Top 50\% & 9645 & $0.0 \%$ & & 9372 & $0.2 \%$ \\
\hline Overall & 7902 & $0.2 \%$ & & 7250 & $0.4 \%$ \\
\hline \hline
\end{tabular}

(b) COL-COL

\begin{tabular}{cccccc}
\hline \hline & \multicolumn{2}{c}{ Married-Couple Households } & & \multicolumn{2}{c}{ Individualist Households } \\
\cline { 2 - 3 } \cline { 5 - 6 } Welfare Percentile & $\bar{c}_{c y c}$ & Cost of Cyc. & & $\bar{c}_{c y c}$ & Cost of Cyc. \\
\hline Bottom 10\% & 2429 & $0.6 \%$ & & 1785 & $1.7 \%$ \\
$10-50 \%$ & 4790 & $0.5 \%$ & & 4450 & $0.8 \%$ \\
Top 50\% & 7561 & $0.3 \%$ & & 7574 & $0.4 \%$ \\
\hline Overall & 6124 & $0.4 \%$ & & 5746 & $0.7 \%$ \\
\hline \hline
\end{tabular}

(c) COL-HS

\begin{tabular}{cccccc}
\hline \hline & \multicolumn{2}{c}{ Married-Couple Households } & & \multicolumn{2}{c}{ Individualist Households } \\
\cline { 2 - 3 } \cline { 5 - 6 } Welfare Percentile & $\bar{c}_{c y c}$ & Cost of Cyc. & & $\bar{c}_{c y c}$ & Cost of Cyc. \\
\hline Bottom 10\% & 2616 & $0.5 \%$ & & 1862 & $1.3 \%$ \\
$10-50 \%$ & 5066 & $0.6 \%$ & & 4481 & $0.9 \%$ \\
Top 50\% & 7887 & $0.3 \%$ & & 7336 & $0.4 \%$ \\
\hline Overall & 6422 & $0.4 \%$ & & 5646 & $0.7 \%$ \\
\hline \hline
\end{tabular}

(d) HS-COL

Table 7: Simulated welfare cost of cyclical fluctuations.

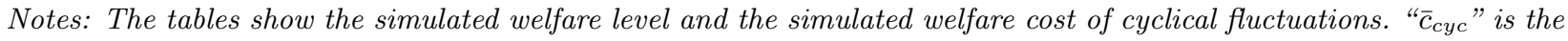
average consumption-equivalent of lifetime utility in the baseline (cyclical) environment, defined in Eq. 8. "Cost of Cyc." is the percentage increase in consumption-equivalent compared to a counterfactual environment in which there are no cyclical fluctuations. Welfare percentiles are based on the distribution of $\bar{c}_{c y c}$. 
In order to quantify the effects of joint decision-making, I compare the baseline model of married-couple households to an individualist model in which individuals make decisions as if they were singles. The comparison reveals that joint decision-making by couples contributes to the counter-cyclicality of women's unemployment rate, particularly among those who do not have a college degree. The effect of joint decision-making on men is ambiguous as their unemployment rate is strongly counter-cyclical even when making decisions as singles. The comparison with individualist households also indicates that joint decision-making is an effective way for married couples to self-insure against aggregate shocks. The simulated welfare cost of cyclical fluctuations experienced by individualist households is $1 / 2$ to $1 / 3$ higher than that experienced by married-couple households, and the difference is larger for households at the bottom of the welfare distribution.

A channel for future research is to account for joint decision-making in the design of Unemployment Insurance (UI) policies that aim to provide relief in recessions. Intra-household risk sharing is substitutable for social welfare programs because both provide insurance (Cullen and Gruber, 2000; Haan and Prowse, 2017). UI extensions in recessions may cause additional moral hazard as the extended benefits discourage countercyclical search effort from both the recipient and his or her spouse.

\section{References}

Aiyagari, S. R. (1994). Uninsured idiosyncratic risk and aggregate saving. The Quarterly Journal of Economics, 109(3):659-84.

Albanesi, S. and Sahin, A. (2018). The Gender Unemployment Gap. Review of Economic Dynamics, 30:47-67.

Alexopoulos, M. and Gladden, T. (2004). The effects of wealth, and unemployment benefits on search behavior and labor market transitions. Econometric Society 2004 North American Summer Meetings 517, Econometric Society.

Biddle, J. and Hamermesh, D. (2013). Wage discrimination over the business cycle. IZA Journal of Labor Policy, 2(1):1-19.

Blundell, R., Pistaferri, L., and Saporta-Eksten, I. (2016). Consumption inequality and family labor supply. American Economic Review, 106(2):387-435.

Card, D., Chetty, R., and Weber, A. (2007). Cash-on-Hand and Competing Models of Intertemporal Behavior: New Evidence from the Labor Market. The Quarterly Journal of Economics, 122(4):1511-1560.

Chiappori, P.-A. and Mazzocco, M. (2017). Static and Intertemporal Household Decisions. Journal of Economic Literature, 55(3):985-1045.

Cullen, J. B. and Gruber, J. (2000). Does Unemployment Insurance Crowd Out Spousal Labor Supply? Journal of Labor Economics, 18(3):546-72. 
Dey, M. and Flinn, C. (2008). Household search and health insurance coverage. Journal of Econometrics, 145(1-2):43-63.

Doepke, M. and Tertilt, M. (2016). Families in Macroeconomics, volume 2 of Handbook of Macroeconomics, chapter 0, pages 1789-1891. Elsevier.

Elsby, M. W., Hobijn, B., and Sahin, A. (2015). On the importance of the participation margin for labor market fluctuations. Journal of Monetary Economics, 72(C):64-82.

Elsby, M. W. L., Shin, D., and Solon, G. (2016). Wage Adjustment in the Great Recession and Other Downturns: Evidence from the United States and Great Britain. Journal of Labor Economics, 34(S1):249291.

Faberman, R. J., Mueller, A. I., Sahin, A., and Topa, G. (2017). Job Search Behavior among the Employed and Non-Employed. NBER Working Papers 23731, National Bureau of Economic Research, Inc.

Flabbi, L. and Mabli, J. (2018). Household Search or Individual Search: Does It Matter? Journal of Labor Economics, 36(1):1-46.

Ganong, P. and Noel, P. (2017). Consumer spending during unemployment: Positive and normative implications. Unpublished manuscript, U. Chicago.

Gourieroux, C., Monfort, A., and Renault, E. (1993). Indirect Inference. Journal of Applied Econometrics, $8(\mathrm{~S}): \mathrm{S} 85-118$.

Guler, B., Guvenen, F., and Violante, G. L. (2012). Joint-search theory: New opportunities and new frictions. Journal of Monetary Economics, 59(4):352-369.

Haan, P. and Prowse, V. (2017). Optimal Social Assistance and Umemployment Insurance in a Life-Cycle Model of Family Labor Supply and Savings. Purdue University Economics Working Papers 1294, Purdue University, Department of Economics.

Hoynes, H., Miller, D. L., and Schaller, J. (2012). Who Suffers during Recessions? Journal of Economic Perspectives, 26(3):27-48.

Jones, S. R. G. and Riddell, W. C. (2006). Unemployment and Nonemployment: Heterogeneities in Labor Market States. The Review of Economics and Statistics, 88(2):314-323.

Juhn, C. and Potter, S. (2007). Is there still an added-worker effect? Staff report, FRB of New York.

Krebs, T. (2007). Job Displacement Risk and the Cost of Business Cycles. American Economic Review, $97(3): 664-686$.

Lentz, R. and Tranaes, T. (2005). Job search and savings: Wealth effects and duration dependence. Journal of Labor Economics, 23(3):467-490. 
Low, H., Meghir, C., and Pistaferri, L. (2010). Wage risk and employment risk over the life cycle. American Economic Review, 100(4):1432-67.

Lucas Jr., R. E. (1987). Models of business cycles. Oxford: Basil Blackwell.

Lundberg, S. (1985). The Added Worker Effect. Journal of Labor Economics, 3(1):11-37.

Mankart, J. and Oikonomou, R. (2017). Household Search and the Aggregate Labour Market. Review of Economic Studies, 84(4):1735-1788.

Mortensen, D. T. and Pissarides, C. A. (1994). Job Creation and Job Destruction in the Theory of Unemployment. Review of Economic Studies, 61(3):397-415.

Ortigueira, S. and Siassi, N. (2013). How important is intra-household risk sharing for savings and labor supply? Journal of Monetary Economics, 60(6):650-666.

Polivka, A. E. and Miller, S. M. (1998). The CPS after the Redesign: Refocusing the Economic Lens. In Labor Statistics Measurement Issues, NBER Chapters, pages 249-289. National Bureau of Economic Research, Inc.

Rothstein, J. (2011). Unemployment Insurance and Job Search in the Great Recession. Brookings Papers on Economic Activity, 43(2 (Fall)):143-213.

Saks, R. E. and Wozniak, A. (2011). Labor Reallocation over the Business Cycle: New Evidence from Internal Migration. Journal of Labor Economics, 29(4):697-739.

Shimer, R. (2012). Reassessing the Ins and Outs of Unemployment. Review of Economic Dynamics, 15(2):127148.

Shimer, R. (2013). Job search, labor-force participation, and wage rigidities. In Advances in Economics and Econometrics. Cambridge University Press.

Shore, S. H. (2010). For better, for worse: Intrahousehold risk-sharing over the business cycle. The Review of Economics and Statistics, 92(3):536-548.

Stancanelli, E. G. F. (1999). Do the rich stay unemployed longer? an empirical study for the uk. Oxford Bulletin of Economics and Statistics, 61(3):295-314.

Tripier, F. (2004). Can the labor market search model explain the fluctuations of allocations of time? Economic Modelling, 21(1):131-146.

Veracierto, M. (2008). On the cyclical behavior of employment, unemployment and labor force participation. Journal of Monetary Economics, 55(6):1143-1157. 


\section{Appendix}

\section{Appendix A. Transitions Between Non-Participation and Unemployment}

In the Current Population Survey (CPS), non-employed individuals are classified as unemployed workers or labor force non-participants based on their reported job search activities. Thus, transitions between the two states can reflect changes in the level of job search effort. Here I highlight two observations based on a sample of married individuals in the CPS. First, the transition rates between unemployment and non-participation exhibit cyclical patterns. Second, the transitions are closely associated with spousal labor force status.

Appendix A.1. Cyclicality

Figure A.4 shows that the monthly rates of transitions between unemployment and non-participation are highly cyclical among married individuals. ${ }^{19}$ Table A.8 shows the correlation of these transition rates with the unemployment rate and the job-finding rate. Specifically, a higher transition rate from unemployment to non-participation correlates with a tight labor market, characterized by a low unemployment rate and a high job-finding rate, while a high transition rate from non-participation to unemployment correlates with a slack labor market.

I compute the transition rates by exploiting the panel structure of the CPS. For example, the transition rate from non-participation to unemployment is computed as the fraction of non-participants who are unemployed a month later. I apply the de-NUN technique introduced by Elsby et al. (2015) to correct potential mistakes in the recorded labor force status of non-employed individuals, which are known as classification errors. ${ }^{20}$

\section{Appendix A.2. Spousal Unemployment Effects}

For married individuals, transitions between unemployment and non-participation may depend on spousal labor force status. To examine this relationship, I estimate two multinomial logistic regressions, in which the response variables are transitions originating from unemployment $\left(l_{0}=U\right)$ and non-participation $\left(l_{0}=N\right)$, respectively. Let $p_{i, t}\left(l_{0}, l_{1}\right)$ be the probability that individual $i$ is in the labor force state $l_{1}$ in period $t+1$ conditional on being in the state $l_{0}$ in period $t$. For each $l_{0} \in\{U, N\}$, let $\eta_{i, t, l_{1}}$ denote the log-odds of transitioning to $l_{1}$ relative to remaining at $l_{0}$ such that:

$$
\eta_{i, t, l_{1}}=\ln \left(\frac{p_{i, t}\left(l_{0}, l_{1}\right)}{p_{i, t}\left(l_{0}, l_{0}\right)}\right)
$$

\footnotetext{
${ }^{19}$ I focus on married individuals in this appendix because they are the population of interest in this paper. The transition rates between unemployment and non-participation of unmarried individuals also exhibit cyclical patterns.

${ }^{20}$ Classification errors can lead to spurious transitions between unemployment and non-participation, resulting in an upward bias in the transition rates in recessions because a non-employment spell is more likely to span multiple survey-rounds. However, Elsby et al. (2015) show that the cyclical patterns of the transition rates are qualitatively robust to classification errors.
} 


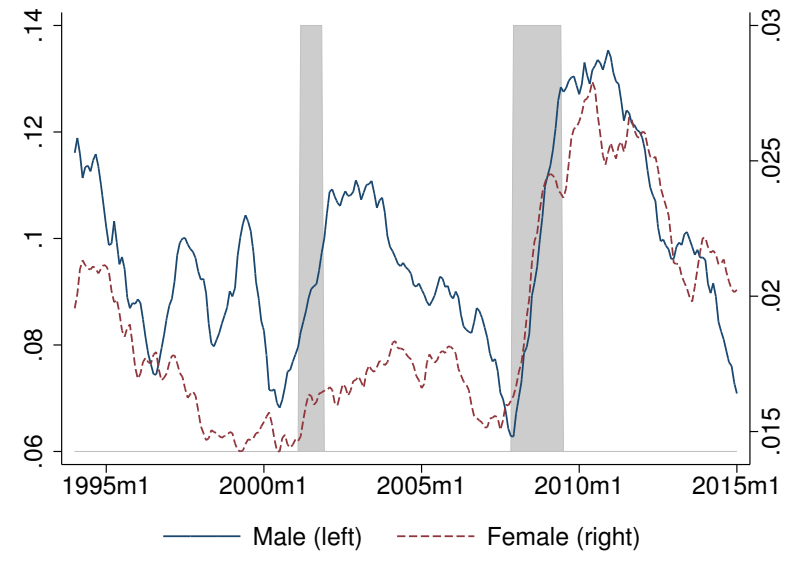

(a) Non-Participation to Unemployment

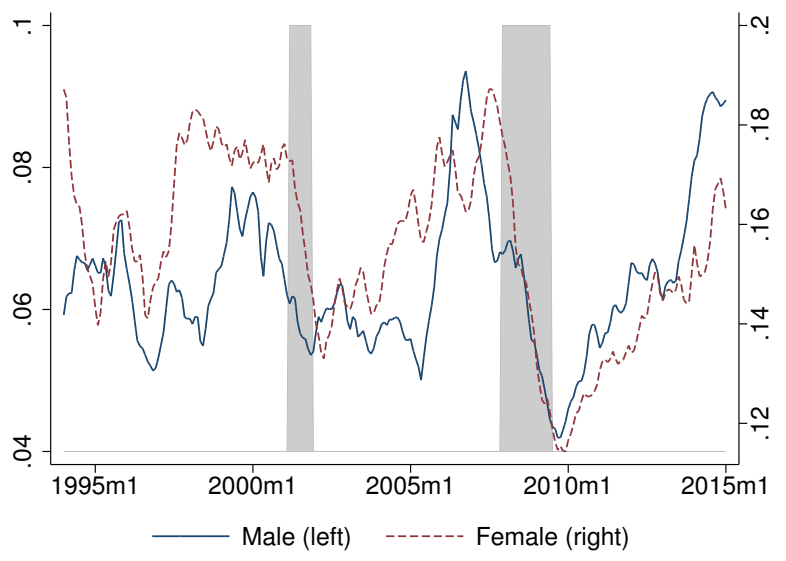

(b) Unemployment to Non-Participation

Figure A.4: Monthly transition rates between unemployment and non-participation of married individuals.

Notes: The graphs show the 12-month moving average of the monthly transition rates computed based on a sample of married individuals age 30-60 with at least high-school education drawn from the matched monthly CPS data from 1994-2014. Shaded areas indicate NBER recessions.

\begin{tabular}{lccccc}
\hline \hline & \multicolumn{2}{c}{ Married Women } & & \multicolumn{2}{c}{ Married Men } \\
& Unemp. Rate & Unemp. to Emp. & & Unemp. Rate & Unemp. to Emp. \\
\cline { 1 - 2 } \cline { 5 - 6 } Non-Particip. to Unemp. & 0.96 & -0.89 & & 0.84 & -0.75 \\
Unemp. to Non-Particip. & -0.84 & 0.75 & & -0.47 & 0.34 \\
\hline \hline
\end{tabular}

Table A.8: Cyclicality of monthly transition rates.

Notes: The table shows coefficients of correlation. "Non-Particip. to Unemp.", "Unemp. to Non-Particip.", and "Unemp. to Emp." are monthly transition rates from non-participation to unemployment, from unemployment to non-participation, and from unemployment to employment, respectively. The unemployment rate and transition rates are 12-month moving averages computed based on a sample of married individuals age 30-60 with at least high-school education drawn from the matched monthly CPS data from 1994-2014. 
and let the regression equation be

$$
\begin{aligned}
\eta_{i, t, l_{1}}= & \sum_{l^{\prime}=U, N} \beta_{l_{1}}^{S P, l^{\prime}} \mathbf{1}_{\left\{l_{i, t}^{s p}=l^{\prime}\right\}}+\sum_{l^{\prime}=U, N} \beta_{l_{1}}^{S P_{0}, l^{\prime}} \mathbf{1}_{\left\{l_{i, t-12}^{s p}=l^{\prime}\right\}} \\
& +\beta_{l_{1}}^{K I D} K I D_{i, t}+\sum_{l^{\prime}=U, N} \beta_{l_{1}}^{K I D, l^{\prime}} K I D_{i, t} \mathbf{1}_{\left\{l_{i, t}^{s p}=l^{\prime}\right\}}+\boldsymbol{\beta}_{l_{\mathbf{1}}}^{\mathbf{0}} \mathbf{X}_{\mathbf{i}}+\beta_{l_{1}}^{U R} U R_{s t(i), t}
\end{aligned}
$$

In Eq. A.1, $l_{i, t}^{s p}$ and $l_{i, t-12}^{s p}$ are, respectively, the current spousal labor force status and the labor force status a year ago. The parameters of interest are $\beta_{l_{1}=U}^{S P, U}$ when $l_{0}=N$ and $\beta_{l_{1}=N}^{S P, U}$ when $l_{0}=U$; these parameters capture the relationship between labor force transitions and spousal unemployment. ${ }^{21} K I D_{i, t}$ is an indicator for having at least one child aged 12 or under. The coefficient $\beta_{l_{1}}^{K I D}$ captures the effect of having children on labor market transitions, while $\beta_{l_{1}}^{K I D, U}$ captures the interaction between spousal unemployment and children. $\mathbf{X}_{\mathbf{i}}$ is a vector containing a constant term, age, race, and spouse's education. Finally, $U R_{s t(i), t}$ is the unemployment rate in the state of residence. ${ }^{22}$

I estimate the regressions based on a sample of married couples drawn from the matched monthly CPS and consider two education levels, a high-school group consisting of individuals who have completed high school but have not finished college and a college group consisting of individuals with at least a college degree.

Table A.10 shows the estimation results for the regression with $l_{0}=N$. For all gender-education groups, a key observation is that $\beta_{l_{1}=U}^{S P, U}$ is positive and significant, suggesting that non-participants who have an unemployed spouse are more likely to increase their search effort relative to those with an employed spouse. $\beta_{l_{1}=U}^{S P, N}$, the effect of spousal non-participation relative to spousal employment, is largely insignificant. Since relatively fewer men are non-participants, the small sample size limits the power of the corresponding estimates for men. Although having kids is negatively related to transitions into both employment and unemployment, its interaction with spousal unemployment $\left(\beta_{l_{1}}^{K I D, U}\right)$ is insignificant.

Table A.11 shows the estimation results for the regression with $l_{0}=U . \beta_{l_{1}=N}^{S P, U}$ is negative in all groups and it is significant among college men and high school women. Similar to the first set of regressions, having children affects the transition rates but independently of spousal employment status except for college men.

Table A.12 summarizes the average spousal unemployment effects. Relative to having an employed spouse, having an unemployed spouse is associated with a substantial increase in the non-participation-to-unemployment transition rate and a substantial decrease in the unemployment-to-non-participation transition rate.

\footnotetext{
${ }^{21}$ Note that the estimates of $\beta_{l_{1}=U}^{S P, U}$ and $\beta_{l_{1}=N}^{S P, U}$ should not be interpreted as indicating a causal effect of spousal unemployment because the spouse's labor force status is likely endogenous.

${ }^{22}$ The correlation between a married couple's employment opportunities due to common local markets or assortative mating may bias the estimation of $\left\{\beta_{l_{1}}^{S P, l^{\prime}}\right\}_{l^{\prime}=U, N}$ (Lundberg, 1985). Controlling for spousal education and previous labor market outcomes as well as the unemployment rate can ease such concerns.
} 


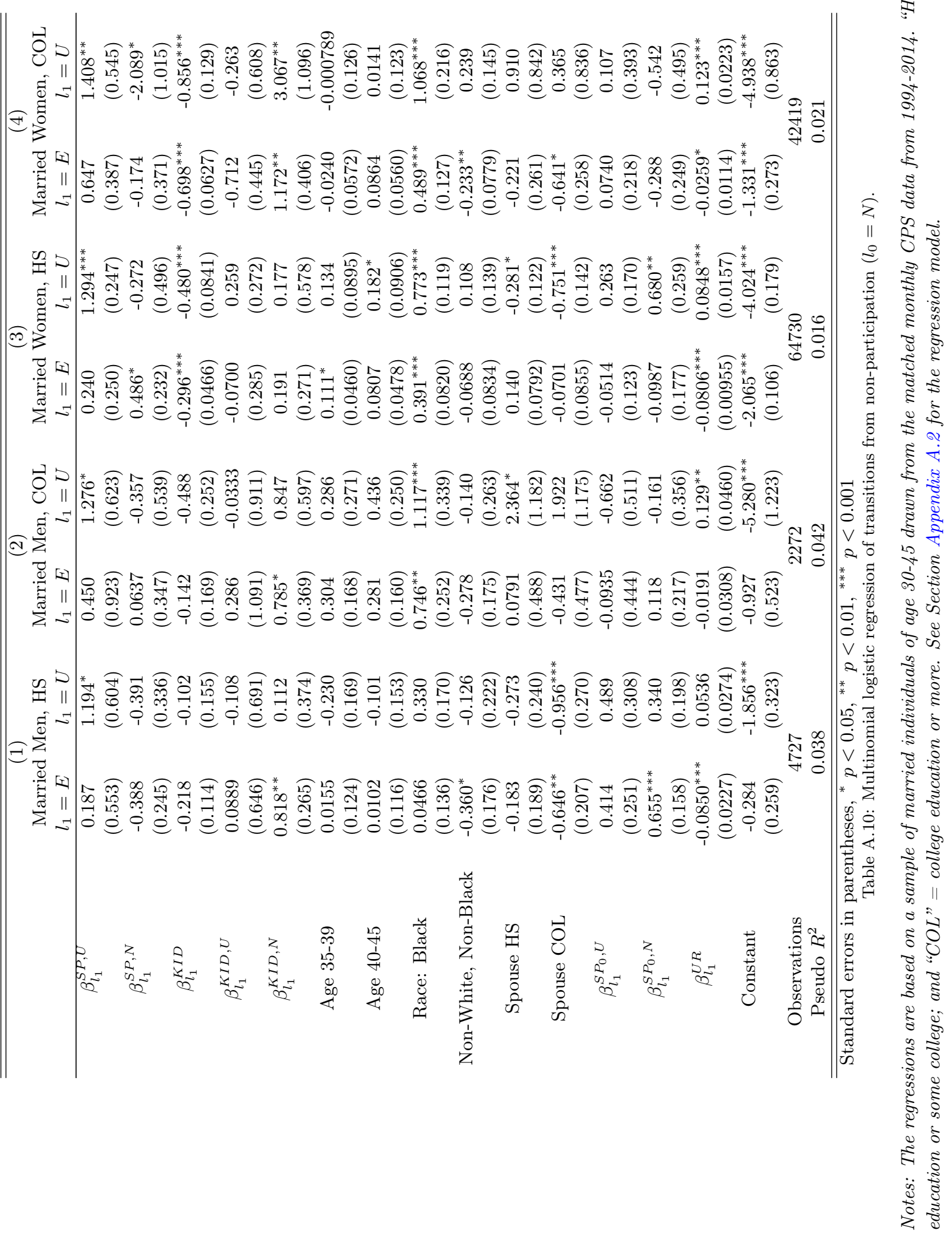




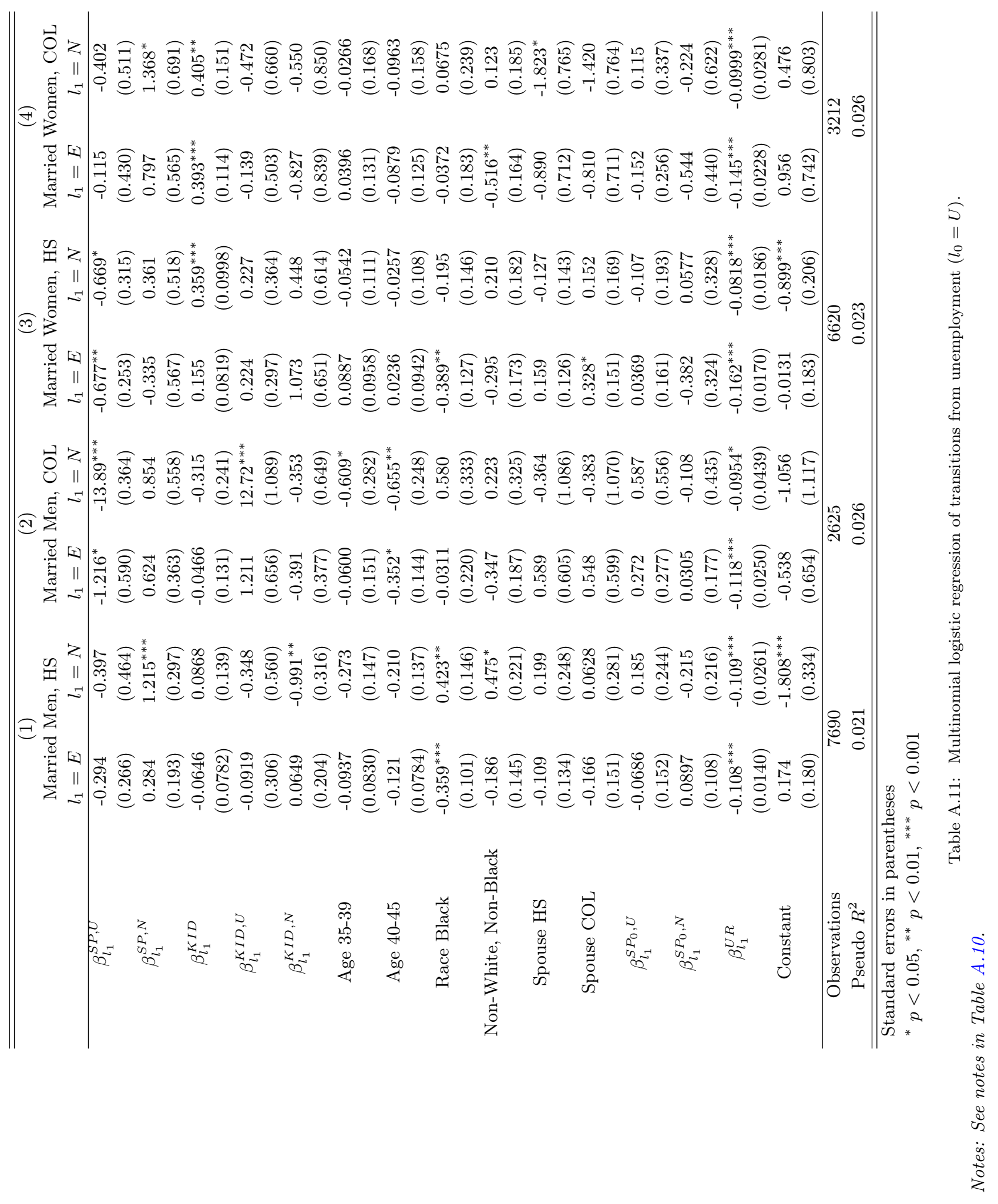




\begin{tabular}{|c|c|c|}
\hline & Spousal Unemployment Effect & Average Transition Rate \\
\hline \multicolumn{3}{|c|}{ Effects on $H S$ Wives } \\
\hline N-to-U & $0.050^{* * *}(0.007)$ & 0.029 \\
\hline U-to-N & $-0.043^{*}(0.017)$ & 0.146 \\
\hline \multicolumn{3}{|c|}{ Effects on COL Wives } \\
\hline N-to-U & $0.027^{* * *}(0.010)$ & 0.017 \\
\hline U-to-N & $-0.059^{*}(0.024)$ & 0.125 \\
\hline \multicolumn{3}{|c|}{ Effects on HS Husbands } \\
\hline $\mathrm{N}-\mathrm{to}-\mathrm{U}$ & $0.131^{* *}(0.045)$ & 0.109 \\
\hline U-to-N & $-0.024^{*}(0.010)$ & 0.069 \\
\hline \multicolumn{3}{|c|}{ Effects on COL Husbands } \\
\hline N-to-U & $0.095(0.056)$ & 0.076 \\
\hline U-to-N & $-0.038^{* *}(0.012)$ & 0.056 \\
\hline
\end{tabular}

Table A.12: Spousal unemployment effects on transition rates between unemployment and non-participation. Notes: The effects are estimated based on a sample of married individuals age 30-45 drawn from the matched monthly CPS data in 1994-2014. "HS" = high school education or some college; and "COL" = college education or more. Spousal unemployment effects are estimated average effects of spousal unemployment relative to spousal employment. See Section Appendix A.2 for the regression model. Full regression results are reported in Tables A.10 and A.11. Standard errors are shown in parentheses. ${ }^{*} p<0.05,{ }^{* *} p<0.01,{ }^{* * *} p<0.001$.

\section{Appendix B. Simplified Model of Couples}

Here I analyze a simplified version of the model described in Section 2 in order to disentangle the various mechanisms affecting the cyclicality of the optimal search intensity. In the simplified model, couples are endowed with an initial asset level $a$ and initial labor force statuses $l_{h}$ and $l_{w}$; they face baseline job finding rates $\lambda_{h}$ and $\lambda_{w}$. I assume that the life cycle consists of two periods. During the first period, couples make consumption and job search decisions to maximize their joint utility over the two periods. Job search outcomes are realized at the beginning of the second period. Households consume all incomes and savings in the second period because there is no preference for bequests.

For simplicity, I assume a zero interest rate $(r=0)$, no subjective discounting $(\beta=1)$, no non-employment income $\left(\mu^{n}=0\right)$, and no separation from employment $(\delta=0)$. The disutility of search intensity and the utility of consumption are specified in Eq. 2 and 3, respectively. As I explain in Section 2, the optimal consumption decision has $c_{h}=c_{w}=c$ where $c$ denotes household consumption. The household utility is

$$
U(c)=2 u(c / 2)
$$

with $U^{\prime}(c)>0$ and $U^{\prime \prime}(c)<0$ for all $c \geq 0$.

To examine the cyclicality of the optimal search intensity, I first investigate how the optimal search intensity varies with the baseline job finding rate conditional on spousal employment status; then, I study how the optimal search intensity depends on spousal employment status. 
In the case that both spouses are non-employed, couples solve the following problem:

$$
\max _{a^{\prime}, s_{h}, s_{w}}\left\{U\left(a-a^{\prime}\right)-\sum_{i=h, w} \kappa_{i}\left(s_{i}\right)+\mathbf{E}_{I n c^{\prime}} U\left(a^{\prime}+I n c^{\prime}\right)\right\}
$$

subject to $0 \leq s_{i} \leq \frac{1}{\lambda_{i}}$ for each $i=h, w$, where $\lambda_{i}$ is the baseline job finding rate for spouse $i$ and $I n c^{\prime}$ is the household income in the second period. The expectation term is

$$
\begin{aligned}
\mathbf{E}_{I n c^{\prime}} U\left(a^{\prime}+I n c^{\prime}\right)= & \left(\lambda_{h} s_{h}\right)\left(\lambda_{w} s_{w}\right) U\left(a^{\prime}+w_{h}+w_{w}\right)+\left(1-\lambda_{h} s_{h}\right)\left(1-\lambda_{w} s_{w}\right) U\left(a^{\prime}\right) \\
& +\left(1-\lambda_{h} s_{h}\right)\left(\lambda_{w} s_{w}\right) U\left(a^{\prime}+w_{w}\right)+\left(\lambda_{h} s_{h}\right)\left(1-\lambda_{w} s_{w}\right) U\left(a^{\prime}+w_{h}\right)
\end{aligned}
$$

Let $a_{n n}^{\prime}, s_{h, n n}$, and $s_{w, n n}$ be policy functions; for brevity, I drop their dependence on initial asset level $a$ and baseline job finding rates $\lambda_{h}$ and $\lambda_{w}$. Interior optimal decisions must satisfy the following first order conditions:

$$
\begin{aligned}
U^{\prime}\left(a-a_{n n}^{\prime}\right)= & \mathbf{E}_{I n c^{\prime}} U^{\prime}\left(a_{n n}^{\prime}+I n c^{\prime}\right) \\
\kappa_{i}^{\prime}\left(s_{i, n n}\right)= & \lambda_{i}\left\{\lambda_{j} s_{j, n n}\left[U\left(a_{n n}^{\prime}+w_{i}+w_{j}\right)-U\left(a_{n n}^{\prime}+w_{j}\right)\right]\right. \\
& \left.+\left(1-\lambda_{j} s_{j, n n}\right)\left[U\left(a_{n n}^{\prime}+w_{i}\right)-U\left(a_{n n}^{\prime}\right)\right]\right\} \text { for } i, j=h, w ; i \neq j
\end{aligned}
$$

Differentiating Eq. B.3 with respect to $\lambda_{i}$ gives

$$
\begin{aligned}
\kappa_{i}^{\prime \prime}\left(s_{i, n n}\right) \frac{\partial s_{i, n n}}{\partial \lambda_{i}}= & \lambda_{j} s_{j, n n}\left[U\left(a_{n n}^{\prime}+w_{i}+w_{j}\right)-u\left(a_{n n}^{\prime}+w_{j}\right)\right]+\left(1-\lambda_{j} s_{j, n n}\right)\left[U\left(a_{n n}^{\prime}+w_{i}\right)-U\left(a_{n n}^{\prime}\right)\right] \\
& +\frac{\partial s_{j, n n}}{\partial \lambda_{i}} \lambda_{i} \lambda_{j}\left\{\left[U\left(a_{n n}^{\prime}+w_{i}+w_{j}\right)-U\left(a_{n n}^{\prime}+w_{i}\right)\right]-\left[U\left(a_{n n}^{\prime}+w_{i}\right)-U\left(a_{n n}^{\prime}\right)\right]\right\} \\
& +\frac{\partial a_{n n}^{\prime}}{\partial \lambda_{i}} \lambda_{i}\left\{\lambda_{j} s_{j, n n}\left[U^{\prime}\left(a_{n n}^{\prime}+w_{i}+w_{j}\right)-U^{\prime}\left(a_{n n}^{\prime}+w_{i}\right)\right]+\left(1-\lambda_{j} s_{j, n n}\right)\left[U^{\prime}\left(a_{n n}^{\prime}+w_{j}\right)-U^{\prime}\left(a_{n n}^{\prime}\right)\right]\right\}
\end{aligned}
$$

The sign of $\frac{\partial s_{i, n n}}{\partial \lambda_{i}}$ is the object of interest. On the left-hand side, $\kappa_{i}^{\prime \prime}\left(s_{i, n n}\right)>0$ by the convexity assumption. The first line on the right-hand side captures the direct effect of a marginal increase in $\lambda_{i}$ : As $i$ is more likely to earn wage $w_{i}$ in the second period, the expected utility in the second period is higher due to a higher household income.

The second line captures the indirect effect due to changes in spousal search effort. The term between the curly brackets is negative because of the concavity of the utility function. Thus, the second line is positive if and only if $\frac{\partial s_{j, n n}}{\partial \lambda_{i}}<0$. Intuitively, there is substitution between search efforts of the two household members. In practice, $\lambda_{i}$ and $\lambda_{j}$ are likely to be correlated due to common aggregate shocks. The greater $d \lambda_{j} / d \lambda_{i}$ is, the more likely it is to have a positive $\frac{\partial s_{j, n n}}{\partial \lambda_{i}}$, which in turn makes the second line negative. I refer to this as the comparative advantage effect.

The third line captures the indirect effect from changes in savings. The term between the curly brackets is again negative because of the concavity of the utility function. Therefore, the third line is negative if and only if $\frac{\partial a_{n n}^{\prime}}{\partial \lambda_{i}}>0$. Intuitively, the third line reflects the substitution between higher savings and higher search intensity as both are ways to provide consumption for the second period. To investigate the sign of $\frac{\partial a_{n n}^{\prime}}{\partial \lambda_{i}}, \mathrm{I}$ 


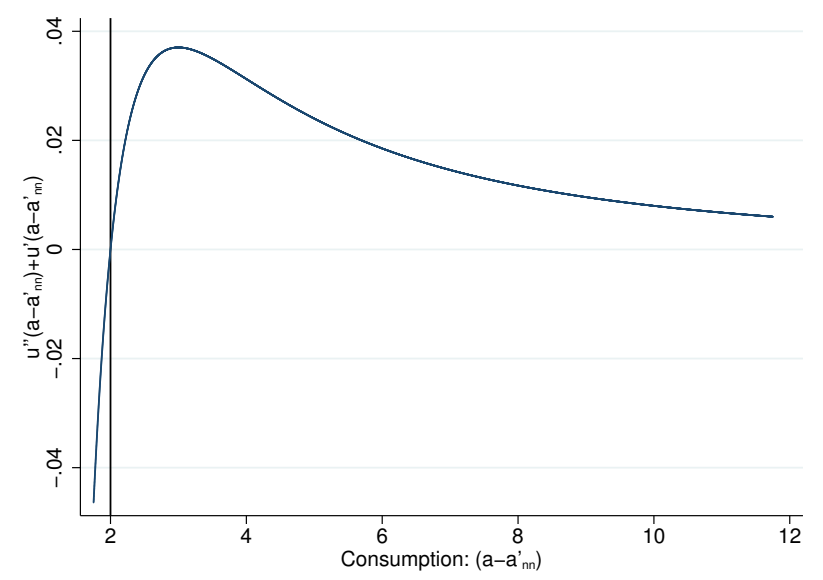

Figure B.5: Denominator of Eq. B.5. $\gamma=2$ in the utility function. $\frac{\partial a_{n n}^{\prime}}{\partial \lambda_{i}}>0$ to the left of the vertical line, and $\frac{\partial a_{n n}^{\prime}}{\partial \lambda_{i}}<0$ to the right of the vertical line.

differentiate Eq. B.2 with respect to $\lambda_{i}$. After rearranging, $\frac{\partial a_{n n}^{\prime}}{\partial \lambda_{i}}$ can be expressed as follows:

$$
\frac{\partial a_{n n}^{\prime}}{\partial \lambda_{i}}=-\frac{s_{i, n n} \lambda_{j} s_{j, n n}\left[U\left(a_{n n}^{\prime}+w_{i}+w_{j}\right)-U\left(a_{n n}^{\prime}+w_{j}\right)\right]+s_{i, n n}\left(1-\lambda_{j} s_{j, n n}\right)\left[U\left(a_{n n}^{\prime}+w_{i}\right)-U\left(a_{n n}^{\prime}\right)\right]}{U^{\prime \prime}\left(a-a_{n n}^{\prime}\right)+U^{\prime}\left(a-a_{n n}^{\prime}\right)}
$$

The numerator is positive because of the monotonicity of the utility function. In the denominator, $U^{\prime \prime}(a-$ $\left.a_{n n}^{\prime}\right)<0$ and $U^{\prime}\left(a-a_{n n}^{\prime}\right)>0$. The sign of the denominator, and hence the sign of $\frac{\partial a_{n n}^{\prime}}{\partial \lambda_{i}}$, varies with the first period's consumption, $a-a_{n n}^{\prime}$. As seen in Figure B.5, the denominator is negative if the first-period consumption is small. In other words, a wealth-poor household is more likely to increase search intensity instead of cutting back consumption in a slack labor market. I refer to the effect of $\lambda_{i}$ on the household's choice between saving and searching as the wealth effect.

Next, I turn to the effects of spousal employment on the optimal search intensity. Relative to a dual-nonemployment household, having an employed spouse is equivalent to an increase in $a$ and an increase in the baseline job finding rate of the spouse to infinity. Therefore, to understand the spousal employment effect, it suffices to show that the optimal search intensity $s_{i, n n}$ decreases with both $a$ and the spouse's $\lambda_{j}$. To illustrate this, I differentiate Eq. B.3 with respect to $a$ and $\lambda_{j}$ in turn and hold the spouse's search intensity $s_{j, n n}$ constant at some fixed level $\hat{s}_{j}$. This gives:

$$
\begin{aligned}
\frac{\partial s_{i, n n}}{\partial a} \kappa_{i}^{\prime \prime}\left(s_{i, n n}\right)= & \frac{\partial a_{n n}^{\prime}}{\partial a} \lambda_{i}\left\{\lambda_{j} \hat{s}_{j}\left[U^{\prime}\left(a_{n n}^{\prime}+w_{i}+w_{j}\right)-U^{\prime}\left(a_{n n}^{\prime}+w_{j}\right)\right]\right. \\
& \left.+\left(1-\lambda_{j} \hat{s}_{j}\right)\left[U^{\prime}\left(a_{n n}^{\prime}+w_{i}\right)-U^{\prime}\left(a_{n n}^{\prime}\right)\right]\right\} \\
\frac{\partial s_{i, n n}}{\partial \lambda_{j}} \kappa_{i}^{\prime \prime}\left(s_{i, n n}\right)= & \frac{\partial a_{n n}^{\prime}}{\partial \lambda_{j}} \lambda_{i}\left\{\lambda_{j} \hat{s}_{j}\left[U^{\prime}\left(a_{n n}^{\prime}+w_{i}+w_{j}\right)-U^{\prime}\left(a_{n n}^{\prime}+w_{j}\right)\right]\right. \\
& \left.+\left(1-\lambda_{j} \hat{s}_{j}\right)\left[U^{\prime}\left(a_{n n}^{\prime}+w_{i}\right)-U^{\prime}\left(a_{n n}^{\prime}\right)\right]\right\} \\
& +\lambda_{i} \hat{s}_{j}\left[U\left(a_{n n}^{\prime}+w_{i}+w_{j}\right)-U\left(a_{n n}^{\prime}+w_{i}\right)\right]-\lambda_{i} \hat{s}_{j}\left[U\left(a_{n n}^{\prime}+w_{j}\right)-U\left(a_{n n}^{\prime}\right)\right]
\end{aligned}
$$


where $\frac{\partial a_{n n}^{\prime}}{\partial a}$ and $\frac{\partial a_{n n}^{\prime}}{\partial \lambda_{j}}$ can be obtained by differentiating Eq. B.2 with respect to $a$ and $\lambda_{j}$ :

$$
\begin{aligned}
\frac{\partial a_{n n}^{\prime}}{\partial a} & =\frac{U^{\prime \prime}\left(a-a_{n n}^{\prime}\right)}{U^{\prime \prime}\left(a-a_{n n}^{\prime}\right)+\mathbf{E}_{I n c^{\prime}} U^{\prime \prime}\left(a_{n n}^{\prime}+I n c^{\prime}\right)} \\
\frac{\partial a_{n n}^{\prime}}{\partial \lambda_{j}} & =\frac{\lambda_{i} s_{i, n n} \hat{s}_{j}\left[U^{\prime}\left(a_{n n}^{\prime}+w_{i}+w_{j}\right)-U^{\prime}\left(a_{n n}^{\prime}+w_{i}\right)\right]+\left(1-\lambda_{i} s_{i, n n}\right) \hat{s}_{j}\left[U^{\prime}\left(a_{n n}^{\prime}+w_{j}\right)-U^{\prime}\left(a_{n n}^{\prime}\right)\right]}{U^{\prime \prime}\left(a-a_{n n}^{\prime}\right)+\mathbf{E}_{I n c^{\prime}} U^{\prime \prime}\left(a_{n n}^{\prime}+I n c^{\prime}\right)}
\end{aligned}
$$

Given the concavity of the utility function, we have $\frac{\partial a_{n n}^{\prime}}{\partial a}>0$ and $\frac{\partial a_{n n}^{\prime}}{\partial \lambda_{j}}>0$. Therefore, we have $\frac{\partial s_{i, n n}}{\partial a}<0$ and $\frac{\partial s_{i, n n}}{\partial \lambda_{j}}<0$, implying that non-employed individuals would search more intensively if the spouse provides less income in the current period or if the spouse is less likely to become employed in the second period. Therefore, spousal non-employed increases search one's search intensity. In addition, if the likelihood of having a non-employed spouse is counter-cyclical, it can cause one's search intensity to vary counter-cyclically. I refer to this as the added-worker effect.

\section{Appendix C. Data Appendix: the Current Population Survey}

\section{Appendix C.1. Job Search Methods by Gender}

Table C.13 shows the list of search methods in the CPS, of which (1)-(9) are active search methods and (10)(12) are passive search methods. Non-employed individuals who reportedly use at least one active method are classified as unemployed workers. As shown in Table C.13, among actively job-seeking unemployed workers, men use a slightly greater number of search methods than women. The most commonly used actives search methods are contacting employer or interviewing and sending resumes or applications.

There are also differences in the usage of specific search methods between men and women. To further investigate these differences, I estimate Probit regressions of the effect of gender on the usage of each search method while controlling for age, unemployment duration, education, race, and year fixed effects. I present the results in Table C.14. Among the most commonly used search methods, women are substantially more likely to send resumes and applications but less likely to contact employer or interview. The differences across genders are potentially driven by preferences or the opportunity cost of the job search activities, or the fact that men and women look for different jobs.

\section{Appendix C.2. Labor Force Measures}

The CPS collects information on employment, availability for work, and job search methods; the labor force status is determined by the responses to these questions. According to the US Bureau of Labor Statistics (BLS), non-employed individuals who are not available for work and have searched for work using at least one active job search method are classified as unemployed workers. ${ }^{23}$ Individuals who are neither employed

\footnotetext{
${ }^{23}$ Individuals who are temporarily laid-off and expecting to be recalled are also classified as unemployed workers.
} 


\begin{tabular}{clcc}
\hline \hline & \multicolumn{1}{c}{ Job Search Method } & Men & Women \\
\hline$(1)$ & Contact employer or interview & 0.62 & 0.56 \\
$(2)$ & Contact public employment agency & 0.26 & 0.20 \\
$(3)$ & Contact private employment agency & 0.11 & 0.08 \\
$(4)$ & Contact friends or relatives & 0.26 & 0.19 \\
$(5)$ & Contact school employment center & 0.03 & 0.03 \\
$(6)$ & Send resumes or applications & 0.51 & 0.55 \\
$(7)$ & Checked union or professional registers & 0.06 & 0.03 \\
$(8)$ & Placed or answered ads & 0.21 & 0.19 \\
$(9)$ & Other active methods & 0.08 & 0.08 \\
$(10)$ & Looked at ads (passive) & 0.31 & 0.30 \\
$(11)$ & Attended training or courses (passive) & 0.01 & 0.01 \\
$(12)$ & Other passive methods (passive) & 0.01 & 0.01 \\
\hline \multicolumn{7}{c}{ Average Number of Methods } & 2.48 & 2.24 \\
\hline \hline
\end{tabular}

Table C.13: Job search methods in the CPS.

Notes: The table shows a list of job search methods and the share of unemployed workers using each method based on the CPS from 1994-2014. (1)-(9) are active search methods and (10)-(12) are passive search methods. The sample contains unemployed workers who reportedly use at least one active search method drawn from married individuals of age 30-45.

nor unemployed are non-participants. Using the CPS, I compute the labor force participation rate as the fraction of individuals in the sample who are employed or unemployed, while the unemployment rate is the fraction of labor force participants who are unemployed.

As I explain in Section 3.1, I obtain my final sample from the CPS after a series of sample restrictions. Table C.15 shows how the labor force participation rate and the unemployment rate vary with each sample selection criterion. Relative to the broader initial sample, men in my final sample have a higher labor force participation rate, while both genders in my final sample have a lower unemployment rate.

I compute labor force transition rates by exploiting the panel structure of the CPS. Given the rotating panel design of the CPS, I am able to match up to three-quarters of the sample households from one month to the next. ${ }^{24}$ For example, the transition rate from the labor force state $S$ to the labor force state $S^{\prime}$ in period $t$ is computed as the fraction of individuals in state $S$ in period $t-1$ who are in state $S^{\prime}$ in period $t$.

\section{Appendix D. Calibration}

\section{Appendix D.1. Wage Levels and Household-Type Distribution}

I choose wage levels $\left\{w_{i}\left(p_{i}\right)\right\}_{i \in\{h, w\} ; p_{i} \in\{L, M, H\}}$ and the distribution of $\left(p_{h}, p_{w}\right)$ based on the "usual weekly earnings" variable in the CPS. The variable records before-tax wages including overtime pay; it is observed

\footnotetext{
${ }^{24}$ Between 1994 and 2014, the exceptions are May to September 1995, during which households cannot be matched across survey rounds.
} 


\begin{tabular}{ccccccc}
\hline \hline & $(1)$ & $(2)$ & $(3)$ & $(4)$ & $(5)$ & $(6)$ \\
\hline Female & $-0.072^{* * *}$ & $-0.060^{* * *}$ & $-0.028^{* * *}$ & $-0.064^{* * *}$ & 0.001 & $0.041^{* * *}$ \\
Age & -0.007 & 0.005 & -0.005 & 0.001 & -0.003 & -0.011 \\
Age Sq. & 0.000 & -0.000 & 0.000 & 0.000 & 0.000 & 0.000 \\
U. Dur. & 0.000 & $0.001^{* * *}$ & $0.000^{* * *}$ & $0.001^{* * *}$ & 0.000 & $0.002^{* * *}$ \\
U. Dur. Sq. & $-0.000^{* *}$ & $-0.000^{* * *}$ & $-0.000^{* * *}$ & $-0.000^{* * *}$ & -0.000 & $-0.000^{* * *}$ \\
Ddu: HS & -0.004 & $0.032^{* * *}$ & $0.021^{* * *}$ & $-0.060^{* * *}$ & $0.011^{* * *}$ & $0.124^{* * *}$ \\
Ddu: COL & $0.026^{* * *}$ & $-0.019^{* * *}$ & $0.080^{* * *}$ & $-0.029^{* * *}$ & $0.040^{* * *}$ & $0.200^{* * *}$ \\
Race: Black & 0.003 & $0.059^{* * *}$ & 0.005 & $-0.020^{* * *}$ & 0.000 & -0.004 \\
Race: Other & $-0.030^{* * *}$ & $-0.020^{* * *}$ & 0.002 & $0.013^{*}$ & -0.001 & $-0.020^{* *}$ \\
\hline Observations & 103970 & 103970 & 103970 & 103970 & 103970 & 103970 \\
Pseudo $R^{2}$ & 0.016 & 0.014 & 0.019 & 0.027 & 0.028 & 0.018 \\
& & & & & & \\
Female & $-0.033^{* * *}$ & $-0.018^{* * *}$ & 0.001 & $-0.010^{* *}$ & -0.001 & 0.001 \\
Age & 0.000 & 0.006 & 0.005 & -0.012 & 0.003 & -0.001 \\
Age Sq. & 0.000 & -0.000 & -0.000 & 0.000 & -0.000 & 0.000 \\
U. Dur. & 0.000 & $0.001^{* * *}$ & -0.000 & $0.002^{* * *}$ & 0.000 & $0.000^{* *}$ \\
U. Dur. Sq. & -0.000 & $-0.000^{* * *}$ & -0.000 & $-0.000^{* * *}$ & -0.000 & $-0.000^{*}$ \\
Ddu: HS & $0.016^{* * *}$ & $0.069^{* * *}$ & $0.033^{* * *}$ & $0.060^{* * *}$ & $0.005^{* * *}$ & $0.006^{* * *}$ \\
Ddu: COL & $0.035^{* * *}$ & $0.094^{* * *}$ & $0.075^{* * *}$ & $0.034^{* * *}$ & $0.008^{* * *}$ & $0.011^{* * *}$ \\
Race: Black & $-0.019^{* * *}$ & $-0.017^{* * *}$ & $-0.019^{* * *}$ & $-0.013^{* *}$ & 0.001 & -0.000 \\
Race: Other & $-0.011^{* * *}$ & $-0.020^{* * *}$ & -0.006 & 0.010 & 0.001 & -0.001 \\
\hline Observations & 103970 & 103970 & 103970 & 103970 & 103970 & 103970 \\
Pseudo $R^{2}$ & 0.038 & 0.010 & 0.025 & 0.012 & 0.006 & 0.126 \\
\hline \hline
\end{tabular}

Table C.14: Marginal effects on the usage of job search methods based on Probit regressions

Notes: Based on a sample of married individuals of age 30-45 drawn from the monthly CPS data from 1994-2014. The sample contains unemployed workers who reportedly use at least one active search method. Year fixed effects are included in the regression model. Columns (1)-(9) are active search methods, and Columns (10)-(12) are passive search methods. See Table C.13 for the list of search methods. ${ }^{*} p<0.05,{ }^{* *} p<0.01,{ }^{* * *} p<0.001$.

\begin{tabular}{lcccc}
\hline \hline & \multicolumn{2}{c}{ LFPR } & \multicolumn{2}{c}{ UR } \\
Sample Restriction & Men & Women & Men & Women \\
\hline (a) Age 30-45 & 0.939 & 0.762 & 0.041 & 0.047 \\
(b) Age 30-45, Married & 0.953 & 0.734 & 0.033 & 0.037 \\
(c) Age 30-45, Married, HS or COL & 0.958 & 0.752 & 0.030 & 0.034 \\
(d) Age 30-45, married, HS or COL, Not Disabled or Retired & 0.977 & 0.767 & 0.030 & 0.034 \\
(e) Final Sample & 0.980 & 0.763 & 0.030 & 0.033 \\
\hline \hline
\end{tabular}

Table C.15: Labor force participation rate and unemployment rate by sample restriction.

Notes: Based on data from matched monthly CPS from 1994-2014. LFPR is the labor force participation rate, and $U R$ is the unemployment rate. See Section 3.1 for details on the sample restriction criteria. 


\begin{tabular}{|c|c|c|c|c|c|c|c|c|c|}
\hline & \multicolumn{2}{|c|}{ HS-HS } & \multicolumn{2}{|c|}{ COL-COL } & \multicolumn{2}{|c|}{ COL-HS } & \multicolumn{2}{|c|}{ HS-COL } \\
\hline & & Data & Model & Data & Model & Data & Model & Data & Model \\
\hline 1 & Mean, Women & 7.72 & 7.72 & 8.24 & 8.28 & 7.77 & 7.83 & 8.18 & 8.18 \\
\hline 2 & St. Dev., Women & 0.56 & 0.44 & 0.66 & 0.51 & 0.62 & 0.47 & 0.57 & 0.45 \\
\hline 3 & Mean, Men & 8.21 & 8.21 & 8.65 & 8.65 & 8.53 & 8.53 & 8.29 & 8.29 \\
\hline 4 & St. Dev., Men & 0.46 & 0.36 & 0.51 & 0.40 & 0.50 & 0.39 & 0.48 & 0.38 \\
\hline 5 & Correlation & 0.12 & 0.11 & 0.12 & 0.11 & 0.06 & 0.06 & 0.11 & 0.09 \\
\hline
\end{tabular}

Table D.16: Moments of the joint distribution of log monthly earnings of married couples.

Notes: The table shows the mean, standard deviation, and coefficient of correlation of the joint distribution of log monthly wages of married couples. "Data" refers to monthly wages computed from the "usual weekly earnings" variable in the CPS from 1994-2014. "Model" refers to observed wages in the simulated data.

in out-going rotations, which are the fourth and the eight interviews of each survey cohort, implying that there are at most two observations per individual.

I take the average of each individual's wage observations and exclude individuals at the top and bottom $1 \%$ in each education group in order to eliminate extreme values due to potential measurement errors. I convert the weekly variable into monthly wages and adjust for inflation using the Consumer Price Index so that all measures are in 2014 dollars.

For $i=h, w$ of each of the four household groups, I compute the mean and the standard deviation of log wages, denoted by $\bar{\omega}_{i}$ and $\sigma_{i}$. I choose wage levels to be $w_{i}\left(p_{i}=L\right)=\exp \left(\bar{\omega}_{i}-\sigma_{i}\right), w_{i}\left(p_{i}=M\right)=\exp \bar{\omega}_{i}$, and $w_{i}\left(p_{i}=H\right)=\exp \left(\bar{\omega}_{i}+\sigma_{i}\right)$. Finally, I choose the distribution of $\left(p_{h}, p_{w}\right)$ so that the means, the standard deviations, and the correlation of the simulated joint distribution of log wages are similar to those in the CPS. As shown in Table D.16, the model matches the wage distribution moments well.

\section{Appendix D.2. Retirement Incomes}

I assume that, in the model, the retirement income $w_{i}^{r}$ of an individual who faces wage $w_{i}$ is calculated as follows:

$$
w_{i}^{r}= \begin{cases}0.9 w_{i} & \text { if } w_{i} \leq 816 \\ 0.9 \times 816+0.32\left(w_{i}-816\right) & \text { if } 816<w_{i} \leq 4917 \\ 0.9 \times 816+0.32 \times(4917-816)+0.15\left(w_{i}-4917\right) & \text { if } w_{i}>4917\end{cases}
$$

The function is continuous and piecewise linear; its slopes and bend points are the same as those used by the Social Security Agency in calculating retirement income levels for individuals who retire at the normal 
retirement age in $2014 .^{25}$ In my model, each individual faces a time-invariant degenerate wage distribution, implying that the retirement income level is deterministic.

\section{Appendix D.3. Aggregate States of the Labor Market}

In the model, the aggregate state $z$ follows a two-state Markov process; it affects the baseline job finding rate and the separation rate. I calibrate the Markov process using the observed monthly job finding rate of unemployed workers. $^{26}$ Specifically, I approximate the observed monthly job finding rate with a two-state Markov process using the maximum likelihood method such that the Good state $(z=G)$ is associated with the higher approximated job finding rate while the Bad state $(z=B)$ is associated with the lower approximated job finding rate. Based on the matched monthly CPS data, the job finding rate is computed for a sample of married individuals as the 12-month moving average of the transition rate from unemployment to employment. In order to better estimate the aggregate state transition rates, I use a sample that covers a longer time span and a wider age range than the sample used in estimating the structural parameters of the model. Figure D.6 shows the approximation result. The aggregate state transition rates $\left(\pi_{z^{\prime}} \mid z^{\prime}\right)$ are shown in Table 1. On average, a Bad state lasts for 3.7 years and a Good state lasts for 6 years.

\section{Appendix E. Numerical Procedure}

For each type of households characterized by the education group $E D U_{h}-E D U_{w}$ and the household type $\left(p_{h}, p_{w}\right)$, I solve the model presented in Section 2 by backward induction from the terminal period $\tau=$ $\tau_{\text {work }}+\tau_{\text {ret }}$. The approach is standard. In each period $\tau$, I solve for the optimal decisions given the state variables and next period's value function. If $\tau \geq \tau_{\text {work }}+1$, there are only savings decisions; if $t \leq \tau_{w o r k}$, there are both savings and job search decisions.

I discretize the asset space with $N_{a}=97$ grid points. The grid is uneven, with more grid points distributed at low asset levels. For $\tau \geq \tau_{\text {work }}+1$, I linearly interpolate the next period's value function and use the Golden-section search technique to find the optimal savings level.

For $\tau \leq \tau_{\text {work }}$, I first solve for the optimal asset level given each combination of search intensity levels $\left(s_{h}, s_{w}\right) \in S\left(l_{h}, \eta_{h}\right) \times S\left(l_{w}, \eta_{w}\right)$ via linear interpolation and the Golden-section search technique. The budget constraint holds with equality and the consumption level of each household member is simply half of the household consumption level, which can be computed from the budget constraint. After the optimal asset level is found for each search intensity combination $\left(s_{h}, s_{w}\right)$, I solve for the optimal search intensity decisions.

\footnotetext{
${ }^{25}$ See https://www.ssa.gov/oact/COLA/piaformula.html.

${ }^{26}$ Compared to the job finding rate, the separation rate affects the cyclicality of the unemployment rate to a lesser extent (Shimer, 2012).
} 


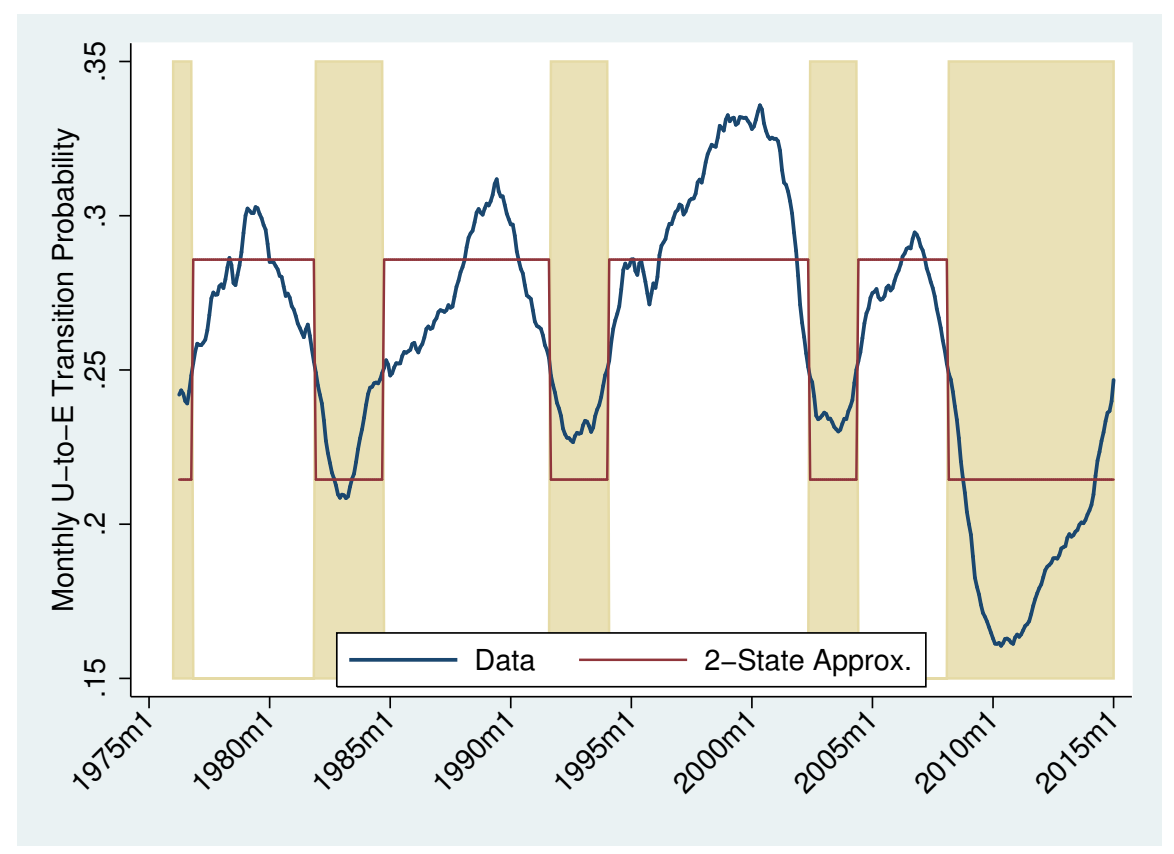

Figure D.6: Monthly job finding rate in the CPS and in the two-state Markov approximation.

Notes: "Data" refers to 12-month moving average of the unemployment-to-employment transition rate computed from the matched monthly CPS data from 1976 to 2014. The sample includes married individuals between age 25 and 60 with at least a high-school degree. "2-State Approx." refers to the unemployment-to-employment transition rate in the approximated two-state Markov process. Shaded areas indicate the Bad state $(z=B)$.

This is trivial when both spouses are employed or under the $\eta$-shock. Otherwise, the search intensity vector $\left(s_{h}, s_{w}\right)$ that maximizes the present value given the optimal asset level is the optimal search decision.

In the retirement stage, the value function is always increasing and concave in asset level. In the working stage, however, the value function is increasing in asset level $a$ but not necessarily concave. ${ }^{27}$ As discussed in the Online Appendix of Low et al. (2010), uncertainties in the model can smooth local convexities. The problem of non-concavity in the value function is not present in the numerical procedure.

\section{Appendix F. Objective Function}

Figure F.7 shows the simulated objective function of the SMM estimation around the estimated parameter values for the HS-HS group; the parameter estimates are shown in Table 2. I vary one parameter at a time while holding the others constant at the estimated values. The figure shows that the objective function achieves a minimum at the estimated values, consistent with the fact that the parameters are well identified. The same conclusion is drawn for the other three groups of households.

\footnotetext{
${ }^{27}$ See Lentz and Tranaes (2005) for a discussion of this problem.
} 


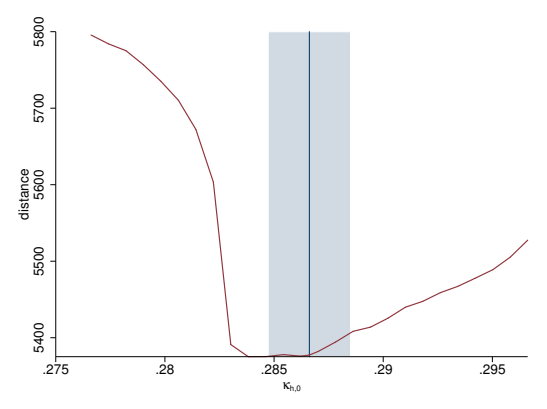

(a) $\kappa_{h, 0}$

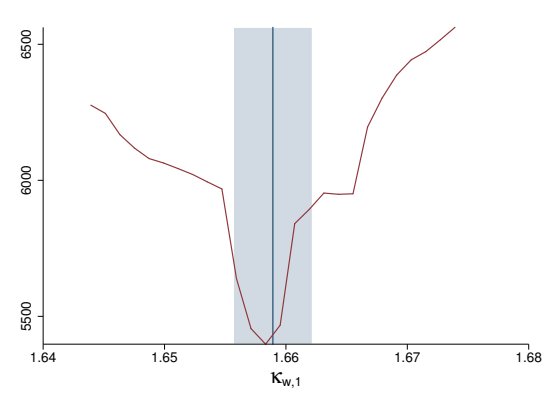

(d) $\kappa_{w, 1}$

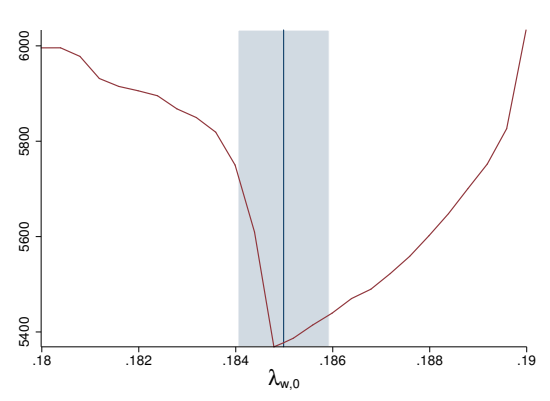

(g) $\lambda_{w, 0}$

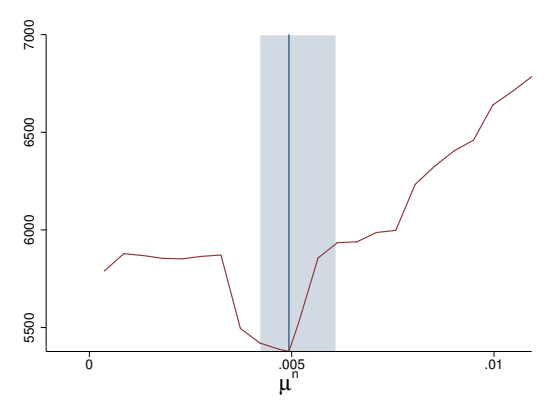

(j) $\mu^{n}$

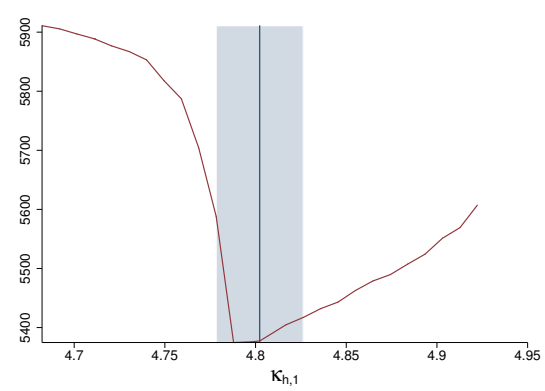

(b) $\kappa_{h, 1}$

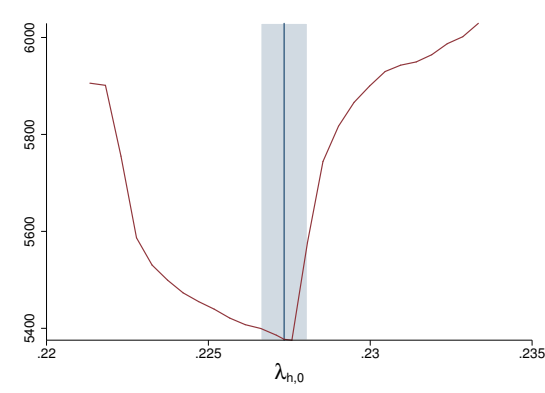

(e) $\lambda_{h, 0}$

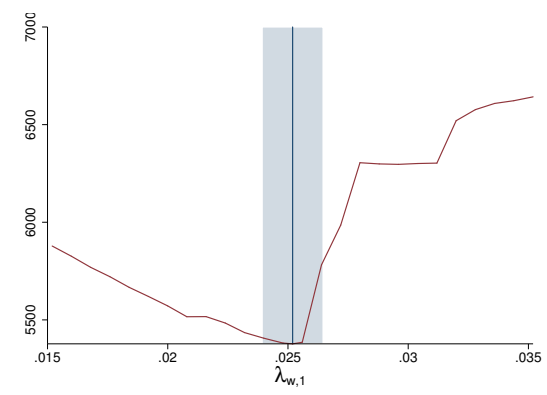

(h) $\lambda_{w, 1}$

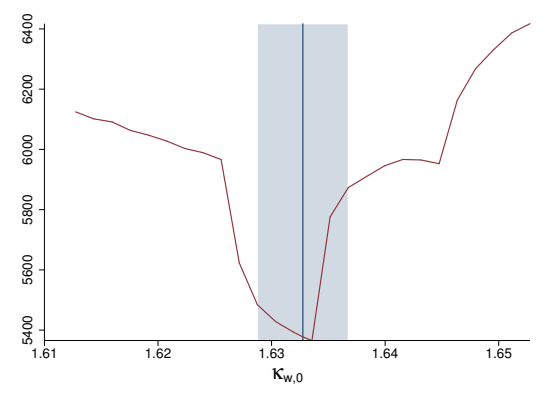

(c) $\kappa_{w, 0}$

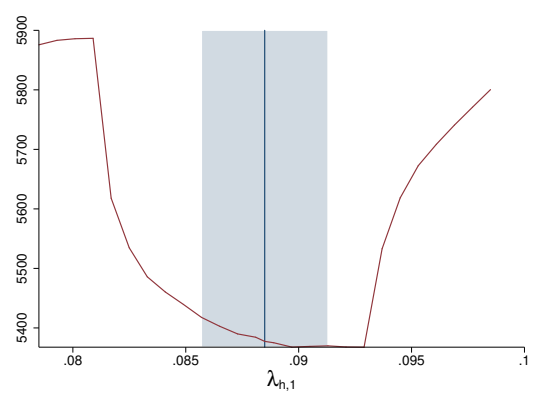

(f) $\lambda_{h, 1}$

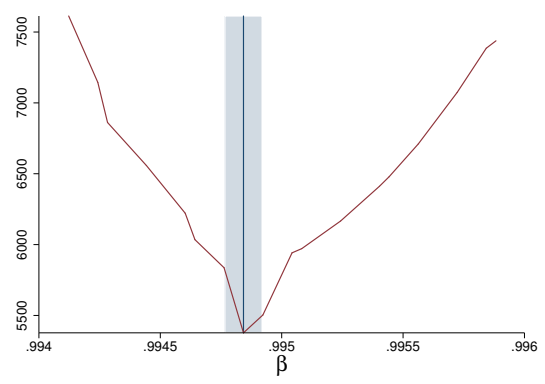

(i) $\beta$

Figure F.7: Simulated objective function at estimated parameter values.

Notes: The graphs are based on simulations from the HS-HS model. Vertical lines indicate the estimated parameter values. Shaded bands indicate the $95 \%$ confidence interval. 


\begin{tabular}{cccccccccc}
\hline \hline$\kappa_{0}^{h}$ & 0.272 & $\kappa_{0}^{w}$ & 1.630 & $\lambda_{h, 0}$ & 0.214 & $\lambda_{w, 0}$ & 0.181 & $\mu_{w}$ & 0.005 \\
$\kappa_{1}^{h}$ & 4.823 & $\kappa_{1}^{w}$ & 1.655 & $\lambda_{h, 1}$ & 0.109 & $\lambda_{w, 1}$ & 0.025 & $\beta$ & 0.995 \\
\hline \hline
\end{tabular}

Table G.17: Estimated parameter values in the model with wage cyclicality

\section{Appendix G. Robustness Check: Wage Cyclicality}

In the baseline model presented in Section 2, I assume that wages $\left\{w_{i}\right\}_{i=h, w}$ do not vary over the business cycle. Elsby et al. (2016) find real wages to be pro-cyclical, while Biddle and Hamermesh (2013) find that the gender wage gap increases in the unemployment rate.

Although the cyclicality of real wages remains an open empirical question in the literature, one may worry about the robustness of the conclusions drawn in this paper when wages are pro-cyclical and the gender wage gap is counter-cyclical. In macroeconomic models with endogenous labor force participation decisions, allowing wages to vary pro-cyclically often leads to counterfactual predictions about the cyclical volatility in unemployment and labor force participation (Shimer, 2013). In my model, counter-cyclical fluctuations in the gender wage gap may attenuate the added-worker effect and the comparative advantage effect.

To demonstrate the robustness of the conclusions, I consider a variation of the baseline model in which there exists wage cyclicality. Specifically, I let $w_{w, z=G}=1.03 w_{w}, w_{w, z=B}=0.97 w_{w}, w_{h, z=G}=1.02 w_{h}$ and $w_{h, z=B}=0.98 w_{h}$; the magnitudes of wage fluctuations are plausible given the empirical findings in the literature. I assume that wages are automatically adjusted for employed workers over the business cycle and estimate the model using the method outlined in Section 3 based on HS-HS households. ${ }^{28}$ The parameter estimates are shown in Table G.17.

In the baseline model, the fact that the gender gap in the baseline job finding rate is cyclical gives rise to the comparative advantage effect. In the current model, there is additionally the cyclical gender wage gap, which also influences the comparative advantage effect. The two types of gender gap counteract one another: The estimation result that $\lambda_{h, 1}>\lambda_{w, 1}$ suggests that women have counter-cyclical comparative advantage in the labor market, whereas the counter-cyclical gender wage gap suggests the opposite.

As shown in Table G.17, the estimated $\lambda_{h, 1}-\lambda_{w, 1}$ is higher than that found in the baseline model, implying that the overall comparative advantage effect remains unchanged despite the counter-cyclical gender wage gap. The fitted moments are shown in Table G.18, which closely follow those of the baseline model shown in Table 3 .

\footnotetext{
${ }^{28}$ The assumption that wages are automatically adjusted is consistent with a real business cycle model in which wages are equal to the value of the marginal product of labor.
} 


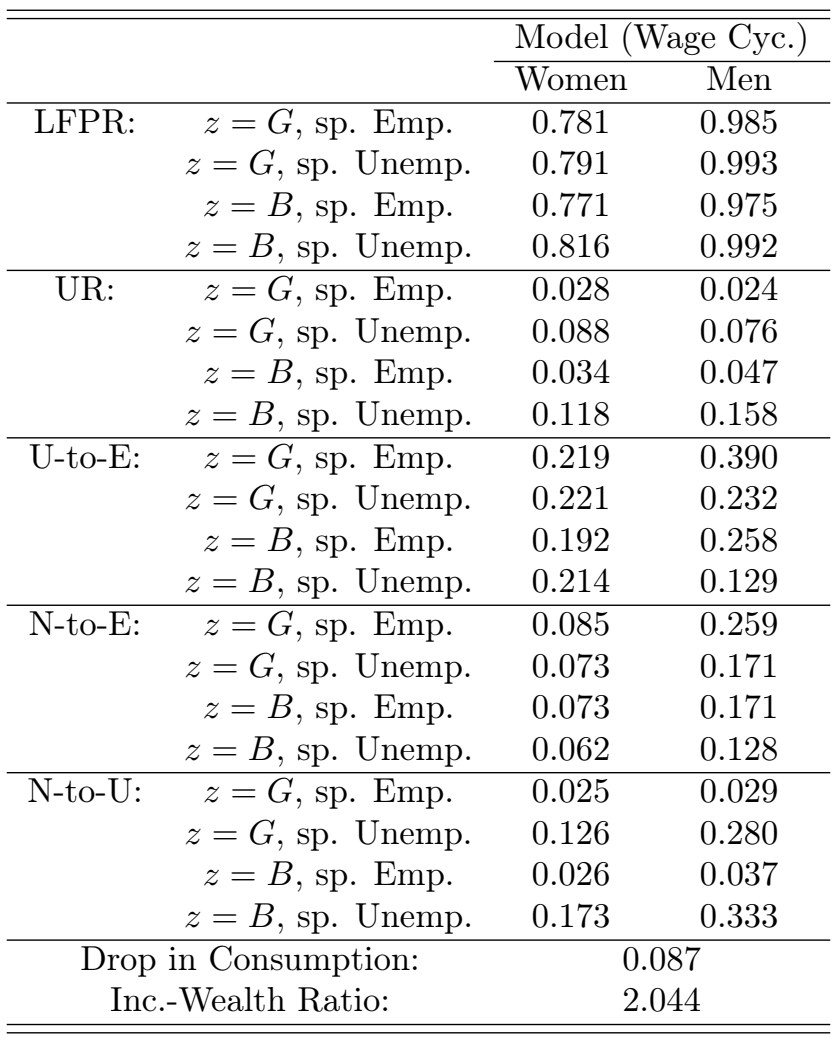

Table G.18: Simulated moments in the model with wage cyclicality

Notes: The table shows moments computed from data simulated from the model with wage cyclicality for HS-HS households. See Appendix Appendix G for details on wage cyclicality. Labor force moments are conditional on the aggregate state and the spouse's labor force status (employed or unemployed). "Inc.-Wealth Ratio" is the median ratio of lifetime average annual income to lifetime average wealth. "Drop in Consumption" is the rate of drop in consumption at the onset of non-employment.

I repeat the exercises carried out in Section 5 to examine the role of joint decision-making on the cyclicality of the unemployment rate and on the welfare cost of cyclical fluctuations. Table G.19 is constructed in the same fashion as Table 6a, which compares the counter-cyclicality of the unemployment rate between the baseline married-couple model and the counterfactual individualist model. The result that joint decision-making contributes to the counter-cyclicality of women's unemployment rate still holds.

Table G.20 is created in the same fashion as Table 7a, which compares the welfare costs of cyclicality experienced by baseline married-couple households to those experienced by counterfactual individualist households. The conclusions drawn from Table 7a carry over. Married couples experience lower welfare costs of cyclicality, and the benefit of being in a married-couple household is the greatest for those at the bottom of the welfare distribution. Overall, plausible cyclical fluctuations in wages and in the gender wage gap do not alter the conclusions drawn in the paper. 


\begin{tabular}{cccccc}
\hline \hline \multirow{2}{*}{ Women } & & $(1) U R_{G}$ & $(2) U R_{B}$ & $(3) U R_{B}-U R_{G}$ & $(4)\left(U R_{B}-U R_{G}\right) / U R_{G}$ \\
& Married & 0.030 & 0.038 & 0.008 & $27.0 \%$ \\
& Individualist & 0.086 & 0.087 & 0.001 & $1.2 \%$ \\
\hline \multirow{2}{*}{ Men } & Married & 0.026 & 0.049 & 0.023 & $91.1 \%$ \\
& Individualist & 0.019 & 0.038 & 0.019 & $103.1 \%$ \\
\hline \hline
\end{tabular}

Table G.19: Cyclicality of the unemployment rate in the model with wage cyclicality

Notes: The table is based on simulated data of HS-HS households. Married women and men are simulated individuals from the married-couple model with wage cyclicality; individualist women and men are simulated individuals from the counterfactual individualist model with wage cyclicality. See Appendix Appendix $G$ for details on wage cyclicality. Columns (1) and (2) show the unemployment rate each aggregate state. Columns (3) and (4) show, respectively, absolute and percentage increases in the unemployment rate from the Good state to the Bad state.

\begin{tabular}{ccccccc}
\hline \hline & \multicolumn{2}{c}{ Married-Couple Households } & & \multicolumn{2}{c}{ Individualist Households } \\
\cline { 2 - 3 } \cline { 5 - 6 } Welfare Percentile & $\bar{c}_{c y c}$ & Cost of Cyc. & & $\bar{c}_{c y c}$ & Cost of Cyc. \\
\hline Bottom 10\% & 2493 & $2.4 \%$ & & 1787 & $3.4 \%$ \\
$10-50 \%$ & 3971 & $1.3 \%$ & & 3534 & $2.4 \%$ \\
Top 50\% & 6064 & $0.5 \%$ & & 5745 & $1.1 \%$ \\
\hline Overall & 4995 & $0.9 \%$ & & 4465 & $1.8 \%$ \\
\hline \hline
\end{tabular}

Table G.20: Simulated welfare cost of cyclical fluctuations in the model with wage cyclicality

Notes: The tables show the simulated welfare level and the simulated welfare cost of cyclical fluctuations. based on HS-HS households. Married-couple households are simulated households from the married-couple model with wage cyclicality; individualist households are simulated households from the counterfactual individualist model with wage cyclicality. See Appendix Appendix G for details on wage cyclicality. " $\bar{c}_{c y c}$ " is the average consumption-equivalent of lifetime utility in the baseline (cyclical) environment, defined in Eq. 8. "Cost of Cyc." is the percentage increase in consumption-equivalent compared to a counterfactual environment in which there are no cyclical fluctuations. Welfare percentiles are based on the distribution of $\bar{c}_{c y c}$. 


\begin{tabular}{cccccccccc}
\hline \hline$\kappa_{0}^{h}$ & 2.198 & $\kappa_{0}^{w}$ & 3.206 & $\lambda_{h, 0}$ & 0.282 & $\lambda_{w, 0}$ & 0.363 & $\mu_{w}$ & 0.005 \\
$\kappa_{1}^{h}$ & 4.187 & $\kappa_{1}^{w}$ & 1.745 & $\lambda_{h, 1}$ & 0.103 & $\lambda_{w, 1}$ & 0.017 & $\beta$ & 0.996 \\
\hline \hline
\end{tabular}

(a) Model with binary search intensity

\begin{tabular}{llllllllll}
\hline \hline$\kappa_{0}$ & 1.366 & $\lambda_{0}$ & 0.048 & $\mu_{h, z=G}^{n}$ & 0.005 & $\mu_{w, z=G}^{n}$ & 0.005 & $\beta$ & 0.995 \\
$\kappa_{1}$ & 1.817 & $\lambda_{1}$ & 0.180 & $\mu_{h, z=B}^{n}$ & 0.005 & $\mu_{w, z=B}^{n}$ & 0.007 & & \\
\hline \hline
\end{tabular}

(b) Model with gender-neutral search parameters

Table H.21: Estimated parameter values in alternative models

Notes: See Section Appendix H for the model with binary search decision. See Section Appendix I for the model with gender-neutral search parameters.

\section{Appendix H. Binary Job Search Decisions}

In this Appendix, I consider a version of the baseline model in which there exist only binary job search decisions. Specifically, I assume that $\boldsymbol{S}_{i}=S_{i}\left(l_{i}=0, \eta_{i}=0\right)=\left\{s_{i, 1}, s_{i, 2}\right\}$. Non-employed individuals searching with intensity $s_{i, 1}$ are classified as non-participants and those searching with intensity $s_{i, 2}$ are classified as unemployed workers. I normalize $s_{i, 2}=1$ for $i=h, w$ and set $s_{i, 1}$ 's to the ratio of the average nonparticipation-to-employment transition rate to the average unemployment-to-employment transition rate; for HS-HS of households, $s_{w, 1}$ and $s_{h, 1}$ are 0.25 and 0.8 , respectively.

I estimate the model using the method outlined in Section 3 and focus on HS-HS households. The estimated parameter values are presented in Table H.21a. Columns "Bi-Srch" in Table H.22 present the simulated labor force moments by aggregate state $z$, which show that the labor force participation rate is counterfactually counter-cyclical.

As I explain in Section 4.3, when job search decisions are multi-level, the optimal search intensity of women varies counter-cyclically among intensive job searchers and pro-cyclically among mild job searchers. The counter-cyclical labor force participation generated in the binary-search model can be explained by the fact that mild job searchers cannot vary their search intensity pro-cyclically. This can be observed from the fact that the simulated transition rate from non-participation to employment is less pro-cyclical than that in the baseline model.

In contrast, men's optimal search intensity in the baseline model is relatively unresponsive to changes in the aggregate state. Consequently, whether the search decision is binary or multi-level does not significantly affect the model's performance in fitting the cyclical patterns in men's labor force moments. 


\begin{tabular}{|c|c|c|c|c|c|c|c|c|c|}
\hline & \multicolumn{4}{|c|}{ Women } & \multicolumn{4}{|c|}{ Men } \\
\hline & & Data & Baseline & Bi-Srch & Gen-Neu & Data & Baseline & Bi-Srch & Gen-Neu \\
\hline \multirow[t]{2}{*}{ LFPR } & $z=G$ & 0.794 & 0.789 & 0.767 & 0.814 & 0.985 & 0.987 & 0.989 & 0.981 \\
\hline & $z=B$ & 0.784 & 0.778 & 0.775 & 0.784 & 0.978 & 0.978 & 0.978 & 0.967 \\
\hline \multirow[t]{2}{*}{ UR } & $z=G$ & 0.029 & 0.031 & 0.031 & 0.031 & 0.025 & 0.026 & 0.026 & 0.031 \\
\hline & $z=B$ & 0.045 & 0.035 & 0.037 & 0.035 & 0.047 & 0.045 & 0.051 & 0.046 \\
\hline \multirow[t]{2}{*}{ U-to-E } & $z=G$ & 0.305 & 0.224 & 0.312 & 0.241 & 0.350 & 0.384 & 0.377 & 0.311 \\
\hline & $z=B$ & 0.205 & 0.201 & 0.291 & 0.192 & 0.251 & 0.277 & 0.238 & 0.250 \\
\hline \multirow[t]{2}{*}{ N-to-E } & $z=G$ & 0.079 & 0.087 & 0.067 & 0.100 & 0.270 & 0.254 & 0.302 & 0.182 \\
\hline & $z=B$ & 0.067 & 0.075 & 0.062 & 0.076 & 0.209 & 0.182 & 0.191 & 0.145 \\
\hline \multirow[t]{2}{*}{ N-to-U } & $z=G$ & 0.021 & 0.029 & 0.030 & 0.034 & 0.103 & 0.048 & 0.042 & 0.056 \\
\hline & $z=B$ & 0.025 & 0.032 & 0.036 & 0.032 & 0.121 & 0.055 & 0.050 & 0.057 \\
\hline
\end{tabular}

Table H.22: Labor force moments by aggregate state in alternative models

Notes: The table is based on simulated HS-HS households. "Data" columns show moments computed from a sample of married couples drawn from the matched monthly CPS data. "Baseline" columns show simulated moments computed from the baseline model (Section 2). "Bi-Srch" columns show simulated moments computed from the model with binary search decision (Section Appendix H). "Gen-Neu" columns show simulated moments computed from the model with gender-neutral search parameters (Section Appendix I).

\section{Appendix I. Gender-Neutral Search Parameters}

Differences in wages and non-employment incomes alone are not sufficient to explain the observed genderasymmetry in labor force moments. To demonstrate this, I consider a version of the baseline model in which the search disutility function and the baseline job finding rate are gender-neutral, while the non-employment income ratio is gender-specific. In other words, I let $\kappa_{i, 0}=\kappa_{0}, \kappa_{i, 1}=\kappa_{1}, \lambda_{i, 0}=\lambda_{0}$, and $\lambda_{i, 1}=\lambda_{1}$ for $i=h, w$, and let $\mu_{i, z}^{n}$ be the non-employment income ratio of household member $i$ in the aggregate state $z$.

I estimate the model using the method outlined in Section 3 and focus on HS-HS households. The estimated parameter values are presented in Table H.21b, and the simulated labor force moments by aggregate state $z$ are shown in Columns "Gen-Neu" of Table H.22.

Overall, the model with gender-neutral search parameters fit the labor force moments poorly. In the model, women's labor force participation rate is too high whereas men's is too low; both are too pro-cyclical. Without gender-specific $\kappa_{0}$ and $\lambda_{0}$, the current model is not able to match the differences in the level and the cyclicality of search intensity across genders. Due to the assumption that couples are unitary decision-makers who pool their incomes, the non-employment income of one spouse inevitably affects both spouses' search decisions in similar ways as a result of the wealth effect. Thus, having gender-specific non-employment incomes has limited ability in helping the model to match the differences in the labor force participation rate across genders.

Another observation is that the current model over-estimates the difference between the unemployment-toemployment transition rate and the non-participation-to-employment transition rate for men. The parameter 
$\kappa_{1}$ disciplines the dispersion in search intensity, which in turn influences the difference between the two job finding rates. Under the current specification, $\kappa_{1}$ is gender-neutral, and its estimated value is smaller than the estimated $\kappa_{h, 1}$ in the baseline model. As non-employment incomes do not influence the dispersion in search intensity, the current model generates the counterfactually large dispersion in the two job finding rates of men. 